\title{
LOS SUJETOS TRANSITIVOS E INTRANSITIVOS CON NÚCLEO NOMINAL COMÚN EN ESPAÑOL. ESTRUCTURA Y EVOLUCIÓN (SIGLOS XIII, XVI Y XIX)
}

\author{
TRANSITIVE AND INTRANSITIVE SUBJECTS \\ WITH NOMINAL COMMON HEAD IN SPANISH. \\ STRUCTURE AND EVOLUTION $\left(13^{\mathrm{TH}}, 16^{\mathrm{TH}}\right.$ AND $19^{\mathrm{TH}}$ \\ CENTURIES)
}

Sergio Bogard El Colegio de México sbogard@colmex.mx

Resumen

Este trabajo ofrece una descripción del proceso de evolución sintáctica y semántica de los sujetos transitivos e intransitivos con núcleo nominal común en español. Con material español del siglo XIII, y español y mexicano de los siglos XVI y xIX, mostraré que, teniendo como punto de partida el orden más frecuente para ambos tipos de sujeto en el XIII, a saber, VS, el XVI ya presenta para el sujeto transitivo un orden dominante SV, en tanto que para el sujeto intransitivo, aunque el orden VS se mantiene como dominante, su productividad ha disminuido drásticamente. Finalmente, el siglo xIX exhibe el inicio de la consolidación del orden SV para ambos tipos de sujeto, dado que dicho orden ya constituye regla en ese momento en el caso del sujeto transitivo, y ya excede el $60 \%$ de aparición en el caso del sujeto intransitivo. Este último comportamiento nos proporciona, además, un nuevo argumento en favor de asumir el siglo XIX como el momento de inicio de una tercera etapa evolutiva en la historia del español, de acuerdo con la hipótesis de Melis, Flores y Bogard 2003.

Palabras Clave: orden de constituyentes, órdenes VS y SV, frase sustantiva con núcleo nominal común, sujetos transitivo e intransitivo, sentido léxico del sujeto nominal

Abstract

This paper offers a description of the syntactic and semantic evolution of Spanish transitive and intransitive subjects with common noun head. Drawing on data from the $13^{\text {th }}$ century as well as from the $16^{\text {th }}$ through the $19^{\text {th }}$ centuries from Peninsular and Mexican Spanish, and based on the fact that the most frequent order for both transitive and intransitive subjects at $13^{\text {th }}$ century is VS, I will argue the following: first, in the $16^{\text {th }}$ century the transitive subject already exhibits a predominant SV order, whereas the intransitive subject maintains the VS order as dominant, although with a drastically diminished productivity; second, the $19^{\text {th }}$ century shows the beginning of the consolidation of the SV order for both types of subjects, given that at that moment it has become the rule for transitive subjects, and it al- 
ready exceedes $60 \%$ of appearance for intransitive subjects. Furthermore, this last behavior provides us with additional support in favor of the claim that the $19^{\text {th }}$ century establishes the starting point of a third evolutionary period in the Spanish language history, a hypothesis put forth by Melis, Flores and Bogard 2003.

KEYwORDS: constituent order, VS and SV orders, noun phrase with common noun head, transitive and intransitive subjects

FECHA DE RECEPCIÓN: 13/08/2018

FECHA DE ACEPTACIÓN: 14/01/2019

\section{Introducción ${ }^{*}$}

Normalmente, en el análisis sintáctico del español, se suele hacer referencia a la función de sujeto sin hacer diferencia entre si se trata de sujeto de verbo transitivo o sujeto de verbo intransitivo. Esto se debe, posiblemente, a que, tratándose el español de una lengua nominativo-acusativa, la forma de marcar ambos tipos de sujeto es la misma y, por lo tanto, en realidad no parece haber una razón que justifique sugerir una distinción en términos de función de oración simple para ambos tipos de sujeto.

Tipológicamente observamos, sin embargo, que las lenguas ergativo-absolutivas, por ejemplo, formalizan de modo distinto ambas funciones, y que el sujeto intransitivo se marca igual que el objeto transitivo. El contraste entre ambos tipos de lenguas nos conduce a pensar que, en el estudio de la gramática de cualquier lengua, conviene tener presente que hablar de sujeto sin considerar el factor transitivo o intransitivo del verbo puede llegar a incidir de manera importante en el análisis, y propiciar que lleguemos a conclusiones cuya generalidad no será del todo confiable.

\footnotetext{
* Le ofrezco mi cumplido agradecimiento a los dictaminadores anónimos de este trabajo, cuyas opiniones y sugerencias me permitieron reestructurarlo para ofrecer un mejor resultado, así como corregir y aclarar algunas de las ideas presentadas en él. La responsabilidad del producto, sin embargo, es mía.
} 
Algo semejante sucede, ya ubicados específicamente en el ámbito de los sujetos intransitivos, ante el hecho de que hay lenguas que muestran comportamientos sintáctico-semánticos diferentes en ese dominio, comportamientos que permiten distinguir entre la clase verbal intransitiva inacusativa y la intransitiva inergativa, como es el caso, por ejemplo, del italiano y el francés, que muestran el fenómeno conocido como intransitividad escindida. Pensando por lo pronto en términos de lenguas nominativo-acusativas, casos como éstos nos vuelven a sugerir que, más allá de que los sujetos transitivos e intransitivos puedan corresponder a una y la misma función sintáctica, no deberían ser estudiados, a priori, como una clase necesariamente unitaria.

Con este contexto, el objeto de este trabajo, descriptivo y sustentado en un enfoque teórico funcional, es mostrar el comportamiento histórico sintáctico y semántico de ambos tipos de sujetos en el análisis de textos españoles del siglo xıII, y mexicanos y españoles de los siglos XVI y XIX, ${ }^{1}$ con el fin, por un lado, de apoyar la idea de que, no obstante que se formalizan gramaticalmente del mismo modo (ambos concuerdan morfológicamente con el verbo conjugado y se sirven de pronombres personales en caso nominativo), presentan suficientes diferencias en

\footnotetext{
${ }^{1}$ Los cortes temporales fueron seleccionados tomando en cuenta momentos cruciales en la historia del español. El siglo XıII, como representante del español medieval, en vista de que en ese siglo Alfonso X el Sabio, rey de Castilla, inicia la transformación del romance castellano en la lengua estándar de su reino, como tal institucionaliza su uso, y acaba consolidando esta política de estado mediante un permanente e intenso trabajo de producción de textos, entre los cuales están los dos utilizados en este trabajo (cf. Fernández-Ordóñez, 2008: 381, nota 20 (387) y 390). El siglo XVI, como representante del periodo del español llamado clásico, dado que es el momento en que una serie de cambios, principalmente de naturaleza fonética, aumentan su difusión y, en consecuencia, intervienen de manera importante en la consolidación de una parte de la estructura de la lengua (cf. Cano Aguilar, 1988: 237-242; Lapesa, 1981: 368 y 385-393; Penny, 1993: cap. 5); y por el lado novohispano porque constituye el siglo en el que, al producirse la conquista de México, en 1521, se inicia y queda formalmente establecida una sociedad en la que, trasplantado desde Europa, el español comienza una nueva aventura histórica, alejado del español de la metrópoli (cf. Bogard, 2010b). Finalmente, el siglo XIX, asumiéndolo como el punto de inicio de un tercer periodo evolutivo en la historia del español (cf. Melis, Flores y Bogard, 2003).
} 
el proceso de evolución de la estructura en que se insertan como para tratarlos por separado; y por otro, de resaltar si en el siglo XIX los cambios se muestran tales que apoyen la tesis presentada en Melis, Flores y Bogard (2003) de que ese siglo constituye el inicio de una tercera etapa evolutiva en la historia del español. En particular mi interés se centra en las frases nominales de sujeto con núcleo sustantivo común, aunque incluiré en el recuento estadístico las frases nominales con núcleo sustantivo propio, y para el efecto propuesto, en este trabajo analizaré la naturaleza léxica del núcleo de sus respectivas frases en términos de referente humano, animado no humano e inanimado, así como su posición relativa con respecto al verbo.

Además de esta introducción y de la conclusión, el trabajo está conformado por un primer apartado en el que presento una muy breve nota sobre los sustantivos, un segundo apartado en el que analizo el sujeto transitivo y un tercero en el que me ocupo del sujeto intransitivo, incluyendo en ambos casos los tres siglos en estudio.

El corpus analizado ha sido extraído de ocho textos: para el siglo xiII, de El Calila e Dimna (ca. 1250) y de la General estoria (1260-1280), para el siglo XVI España, de El Lazarillo de Tormes (1554) y de Las moradas (1588), de Santa Teresa de Jesús, para el siglo xvi México, de las Cartas de Relación (1522 y 1526), de Hernán Cortés, y de la Carta autógrafa de Rodrigo de Albornoz al emperador Carlos V (1525, publicada por Concepción Company en los Documentos Lingüísticos de la Nueva España, 1994), para el siglo xıx España, de La Regenta (1870-1880), de Leopoldo Alas "Clarín", y para el siglo xIx México, de Los bandidos de Río Frío (1880), de Manuel Payno. ${ }^{2}$

\footnotetext{
${ }^{2}$ A continuación anoto el corpus revisado de cada texto, así como, entre paréntesis, la forma de cita utilizada en los ejemplos. Calila e Dimna (Calila): de sus 18 capítulos (267 páginas), revisamos un promedio de tres páginas de cada uno de los capítulos impares, para un total aproximado de $27 \mathrm{pp}$. General estoria. Segunda parte, tomo I (GE): de los 501 capítulos contenidos en 457 páginas (Josué 110 capítulos, Jueces 217 y Tebas 174), revisamos, de Josué cinco capítulos (6 pp.), de Jueces cinco (8 pp.) y de Tebas cinco (5 pp.), para un total de 15 capítulos y 18 pp. Lazarillo de Tormes (LT): revisamos, de la edición trilinear del texto editado por J. V. Ricapito, de la edición de Amberes, del capítulo primero las páginas 3 a 11, del tercero las páginas 37 a 51, del
} 


\section{Una muy breve nota sobre los sustantivos}

Tomando en consideración que cuando el sujeto es explícito en español, además de mediante un pronombre tónico, se formaliza mediante una frase sustantiva o nominal, es inevitable comenzar con una breve descripción que nos permita identificar, sobre el análisis, la diferencia en relación con el tipo de significado que portan los sustantivos propios y los sustantivos comunes, de modo que no la repitamos en cada sección, una vez que ha sido presentada.

Por un lado, está la clase de los sustantivos propios, los cuales identifican una entidad del mundo entre otras más, sin dar cuenta de los rasgos o propiedades que la conforman (NGLE, 2010: \$12.1.2a), debido a que, en palabras de Fernández Leborans (1999: \$2.1.1, 80) “no significa una 'clase’ léxicamente identificable mediante un conjunto de rasgos semánticos codificados", como sucede con el sustantivo común. En este sentido presentan importantes restricciones distribucionales, reflejo formal de que semánticamente sólo denotan y carecen de connotación, ${ }^{3}$ como es el caso de que únicamente bajo ciertas condiciones comunica-

quinto las páginas 63 a 69, y completo el séptimo y último capítulo, para un total de 35 pp. Las moradas (Moradas): de las siete moradas que conforman la obra, el corpus se integró con la revisión del primer capítulo de cada una de las cuatro moradas impares, en particular con siete páginas de cada una de las primera, tercera y séptima moradas, y nueve de la quinta, para un total de 30 pp. Cartas de Relación (Cortés): revisamos la tercera (1522) y la quinta (1526). De la tercera tomamos las páginas 115 a 118, 156 a 159 y 198 a 201, y de la quinta las páginas 242 a 245, 279 a 284 y 319 a 322, con un total de 26 páginas. Carta autógrafa de Rodrigo de Albornoz al emperador Carlos $V$ (DLNE), de 1525: de las 25 páginas que la conforman, revisamos de la página 23 a la 25 , de la 32 a la 35 y de la 43 a la 46, para un total de 11 pp. La Regenta (Regenta): de los 15 capítulos que integran el primer volumen de la edición de Sobejano, incorporamos al corpus, del capítulo 4 las páginas 184 a 192, del 7 las páginas 275 a 282, del 10 las páginas 367 a 374, y del 13 las páginas 478 a 485, para un total de 33 pp. Los bandidos de Río Frío (Bandidos): de los 54 capítulos que conforman la primera parte, integramos al corpus, del capítulo 13 las páginas 83 a 89, del 27 las páginas 195 a 204, del 40 las páginas 325 a 330, y del 54 las páginas 448 a 456; en total 32 pp.

${ }^{3}$ El significado de los sustantivos propios no se caracteriza como la expresión de un conjunto de propiedades, sino que individualiza, de modo que particulariza y dota de referencia única a un individuo que forma parte de un universo de individuos pertenecientes a una misma clase, y lo hace asignándole un nombre que no porta 
tivas de cercanía afectiva acepta ser modificado por un posesivo, como en mi Marcela hizo un muy buen examen, o por un artículo, si el efecto comunicativo ha de ser afectivo o despectivo, como en el Juan no pudo resolver el problema, o por una $\mathrm{FN}$ en aposición, como en Eréndira, una gran amiga (cf. Company, 2009: 20-23).

En contraste, por otro lado, los sustantivos comunes, que dan nombre a todos los individuos integrantes de una clase mediante la identificación de algunos rasgos o propiedades que permiten agruparlos como esa clase (Bello, 1945 [1847]: \$100, Bosque, 1999: \$1.1, 5, NGLE, 2010: \$12.1.2a), no muestran restricción distribucional alguna, dado que pueden ampliar la estructura de su frase mediante expansiones a ambos lados del respectivo núcleo nominal, como reflejo de la riqueza semántico-pragmática que formalizan en el plano discursivo para llevar a efecto su función comunicativa ( $c f$. Company, 2009: 20 y Bogard, 2009: 64). El resultado es que frente a la naturaleza restrictiva y per se individualizante del sustantivo propio, la diversidad léxica del sustantivo común expande las posibilidades temáticas a las que puede recurrir el usuario de la lengua en el flujo comunicativo en el que interviene.

\section{Sujetos transitivos}

\subsection{Siglo XIII}

Comencemos el análisis de los sujetos transitivos mediante la revisión del corpus correspondiente al corte medieval seleccionado. Para este efecto véase el cuadro 1.

\begin{tabular}{|l|l|l|l|}
\hline S. XIII & $\mathrm{S}_{\mathrm{tr}}-\mathrm{V}$ & $\mathrm{V}-\mathrm{S}_{\mathrm{tr}}$ & Total \\
\hline Núcleo nominal propio & $23(41 \%)$ & $33(59 \%)$ & $56(100 \%)$ \\
\hline Núcleo nominal común & $48(41.4 \%)$ & $68(58.6 \%)$ & $116(100 \%)$ \\
\hline Total & $71(41.3 \%)$ & $101(58.7 \%)$ & $172(100 \%)$ \\
\hline
\end{tabular}

Cuadro 1. Sujeto transitivo siglo xirr: orden y tipo de núcleo nominal

significado en términos de las propiedades identificativas que denotan a una clase de objetos (cf. Bogard, 2009: 60). 
En mi material del siglo XIII aparece un total de 172 oraciones con sujeto transitivo explícito, incluyendo tanto frases nominales con núcleo sustantivo común como frases nominales con núcleo sustantivo propio. De ellas, el 32.6\% (56/172) presenta el sujeto formalizado mediante una FN con núcleo nominal propio, y los 56 sujetos portan una referencia humana, mientras que el $67.4 \%$ (116/172) lo presenta codificado como una FN con núcleo nominal común. Esta diferencia, que, como se aprecia, favorece al sujeto transitivo explícito con núcleo nominal común, halla su explicación, principalmente, en la naturaleza funcional característica de cada uno de esos tipos de núcleo nominal, como recordamos en $\$ 1$.

Consideremos ahora la posición del sujeto transitivo en relación con su verbo. En el caso del sujeto transitivo con núcleo nominal propio, el 41\% (23/56) antecede a su verbo, en tanto que el 59\% (33/56) se coloca después de él. Similar comportamiento exhibe el sujeto transitivo con núcleo nominal común, en cuyo caso el $41.4 \%$ (48/116) se antepone a su verbo y el $58.6 \%$ $(68 / 116)$ se le pospone. Los textos revisados del siglo XIII muestran, en conclusión, que el sujeto transitivo tiende a posponerse al verbo, tanto si su núcleo nominal es propio como si es común. Y esta distribución aparentemente no está motivada por diferencias en el tipo de texto, dado que el material recopilado de cada una de las dos obras revisadas se comporta de la misma forma, como se aprecia en los cuadros (2) y (3).

\begin{tabular}{|l|l|l|l|}
\hline S. XIII & $\mathrm{S}_{\mathrm{tr}}-\mathrm{V}$ & $\mathrm{V}-\mathrm{S}_{\mathrm{tr}}$ & Total \\
\hline Núcleo nominal propio & $3(33.3 \%)$ & $6(66.7 \%)$ & $9(100 \%)$ \\
\hline Núcleo nominal común & $26(45.6 \%)$ & $31(54.4 \%)$ & $57(100 \%)$ \\
\hline Total & $29(44 \%)$ & $37(56 \%)$ & $66(100 \%)$ \\
\hline
\end{tabular}

Cuadro 2. Sujeto transitivo siglo xıII: orden y tipo de núcleo nominal, Calila

\begin{tabular}{|l|l|l|l|}
\hline S. XIII & $\mathrm{S}_{\mathrm{tr}}-\mathrm{V}$ & $\mathrm{V}-\mathrm{S}_{\mathrm{tr}}$ & Total \\
\hline Núcleo nominal propio & $20(42.6 \%)$ & $27(57.4 \%)$ & $47(100 \%)$ \\
\hline Núcleo nominal común & $22(37.3 \%)$ & $37(62.7 \%)$ & $59(100 \%)$ \\
\hline Total & $42(39.6 \%)$ & $64(60.4 \%)$ & $106(100 \%)$ \\
\hline
\end{tabular}

Cuadro 3. Sujeto transitivo siglo XIII: orden y tipo de núcleo nominal, GE 
En ambos cuadros es posible advertir que el comportamiento posicional de los sujetos transitivos en relación con el verbo en el material de los dos textos analizados es el mismo, a saber, la presencia de un sujeto transitivo nominal favorece el orden $\mathrm{V}-\mathrm{S}_{\text {tr }}$. Véanse a continuación ejemplos de dichos sujetos con ambos órdenes, con el verbo en cursiva y la FN de sujeto en negritas:

\section{$\mathrm{S}_{\mathrm{tr}}-\mathrm{V}$}

(1)a. Así que un caçador armó sus lazos, et cayó ý el gato (Calila, 268) Otrosí el omne entendido non debe poner su amor con ninguno sinon

después que lo provare (Calila, 317)

Ell obispo Lucas lo cuenta assi (GE, 54, XXXIII, 1, 9-10)

Los adeuinos cataron lo, e uinieron al rey (GE, 335, CCXXXV, 2, 19-20)

b. et la gulpeja oyó aquella boz (Calila, 135)

Dizen que un cuervo vio andar una perdiz (Calila, 304)

c. ca el fuerte viento non quebranta las chicas pajas (Calila, 136) Et si la flaqueza te lo fizo dexar, que non lo pudiste tener, esto es aún peor (Calila, 260)

$\mathrm{V}-\mathrm{S}_{\mathrm{tr}}$

(2)a. Et estovo sienpre cuitado fasta que fue sabido por toda la tierra, et lo entendieron sus ricos omnes et toda su compaña (Calila, 283)

degollaua los alli aquel rey en sacrificio de sos dioses (GE, 26, XI, 2, 9-10)

et allí tenien los thebanos el mayor estudio de sos sacrificios e el mayor bollicio dellos (GE, 191, LXVI, 2, 4-6)

b. Por alguna cosa faze este mur lo que faze (Calila, 211)

Agora contar uos emos por quel auenimiento contescio a aquel infante Acteon quel mataron los sos canes (GE, 150, XXII, 1, 2628) 
c. mas una cosa te quiero rogar et pedírtela en merçed, et fázmela pedir el amor que te he (Calila, 285)

et amas las encierra la mar de la una part (GE, 81, LV, 1, 9-10)

Sobre esta base, es necesario revisar la naturaleza léxica de los sujetos con núcleo nominal común, de modo que podamos apreciar si ése puede ser un factor que incida en el orden relativo entre los sujetos transitivos y su verbo. ${ }^{4}$ En el cuadro 4 podemos apreciar que ese tipo de sustantivos presenta un comportamiento proporcionalmente semejante tanto si anteceden como si se posponen a su verbo.

\begin{tabular}{|l|l|l|l|l|}
\hline S. XIII & Humano & $\begin{array}{l}\text { Animado } \\
\text { no humano }\end{array}$ & Inanimado & Total \\
\hline $\mathrm{S}_{\mathrm{tr}}-\mathrm{V}$ & $30(62.5 \%)$ & $11(22.9 \%)$ & $7(14.6 \%)$ & $48(100 \%)$ \\
\hline $\mathrm{V}-\mathrm{S}_{\mathrm{tr}}$ & $37(54.4 \%)$ & $18(26.5 \%)$ & $13(19.1 \%)$ & $68(100 \%)$ \\
\hline
\end{tabular}

Cuadro 4. Sujeto transitivo siglo XIII:

naturaleza léxica del núcleo nominal común

En efecto, con el orden $\mathrm{S}_{\mathrm{tr}} \mathrm{V}$ encontramos $85.4 \%$ (41/48) sujetos animados, divididos en $62.5 \%$ (30/48) con referencia humana (véanse los ejemplos en 1a) y $22.9 \%(11 / 48)$ con referencia animada no humana (ejemplos en $1 \mathrm{~b}$ ), así como 14.6\% (7/48) con referencia inanimada (ejemplos en 1c). Y con el orden $\mathrm{VS}_{\mathrm{tr}}$ hallamos $80.9 \%$ (55/68) sujetos animados, divididos en $54.4 \%$ $(37 / 68)$ con referencia humana (ejemplos en $2 a)$ y $26.5 \%(18 / 68)$ con referencia animada no humana (ejemplos en $2 \mathrm{~b}$ ), además de $19.1 \%$ (13/68) con referencia no animada (ejemplos en $2 \mathrm{c}) .^{5}$

\footnotetext{
${ }^{4}$ Por lo pronto, este factor no interviene en el caso de los sujetos transitivos cuya frase nominal corresponde a sustantivo propio, dado que en el $100 \%$ de los casos el nombre propio refiere a seres humanos o a Dios.

${ }^{5}$ La relativamente alta proporción de sujetos transitivos con referencia animada no humana está motivada, sustancialmente, por la cantidad de personajes representados por animales 'humanizados' presentes en el Calila e Dimna, texto de naturaleza doctrinal. Como se podrá apreciar en la información de los textos correspondientes a los siglos subsecuentes, su frecuencia de aparición disminuye casi totalmente, en beneficio de la referencia humana.
} 
Como puede observarse, con ambos órdenes predomina, con mucho, la referencia animada, y en particular humana, del sujeto transitivo, y en ambos casos la diferencia respectiva de apenas 4 puntos porcentuales $\left(\mathrm{S}_{\mathrm{tr}} \mathrm{V} 85.4 \%\right.$ por $\left.\mathrm{VS}_{\mathrm{tr}} 80.9 \%\right)$ no parece ser significativa para sugerir una justificación al orden alternante entre el verbo transitivo y su sujeto, como tampoco la diferencia porcentual, también de 4 puntos, entre los sujetos transitivos con referencia no animada para ambos órdenes $\left(\mathrm{S}_{\mathrm{tr}} \mathrm{V}\right.$ $14.6 \%$ por $\left.\mathrm{VS}_{\mathrm{tr}} 19.1 \%\right)$.

Y no es raro este comportamiento léxico y cuantitativo de los sujetos transitivos, muy especialmente cuando la referencia animada se particulariza como referencia humana, como se puede cotejar en la columna correspondiente del cuadro 4, debido a que su naturaleza semántica prototípica se ha identificado como típicamente agentiva. En efecto, ya Givon (1976: 152-153) señalaba como normal que la función semántica de agente se formalice en la función sintáctica de sujeto - se refiere al transitivo-, y que agente y sujeto establezcan un correlato bastante generalizado con la función discursiva de tópico.

En este punto, y a propósito del elevado porcentaje de los sujetos transitivos con referencia animada, y en particular humana, no hay que perder de vista que éste es el tipo de entidades que más claramente pueden construirse como agentes, en otras palabras, las que mediante su capacidad de transmisión de energía generan la noción de un mayor dinamismo del evento expresado en el predicado verbal, y producen o instigan algún cambio en el paciente ${ }^{6}$ (cf. Maldonado, 1999: 15, 23; Melis, 2012:

\footnotetext{
${ }^{6}$ Semejante es la perspectiva planteada por Cruse (1973: 19-21) salvo que él incluye, además de entidades vivientes, también entidades inanimadas como instrumentos, cierto tipo de máquinas y lo que llama agentes naturales, a los que podemos asociar con participantes causantes. Ramchand (2008: 23-24), por su parte, incluye la causación en la noción de agentividad, y asume la existencia del primitivo 'iniciador' como característico del sujeto transitivo (en sus términos, argumento externo), al que define como "an entity whose properties/behaviour are responsable for the eventuality coming into existence”. Nuevamente, y asociado con la noción de causación, en este caso encontramos "agentes" no animados que por sus propiedades naturales pueden iniciar el desarrollo de un evento.
} 
19-20), sea de manera volitiva y/o intencional. ${ }^{7}$ En resumen, la noción semántica de agente se constituye en la base conceptual que caracteriza a los sujetos transitivos prototípicos. Dicho de otro modo, e independientemente de la posición relativa que ocupen con respecto al verbo, los sujetos transitivos prototípicos formalizan entidades cuyas propiedades características sólo se encuentran, en condiciones normales, en individuos preferentemente humanos. Esto sugiere una razón de por qué, en nuestro corpus del siglo XIII, en ambas posiciones relativas con respecto al verbo, el sujeto transitivo con referencia animada, y particularmente humana, tiene el mayor porcentaje de ocurrencias, pero no explica su colocación antepuesta o pospuesta en relación con su verbo.

Si en la búsqueda de esa explicación revisamos los ejemplos de las oraciones correspondientes, vemos que, en relación con el orden $\mathrm{S}_{\mathrm{tr}} \mathrm{V}$ - los ejemplos en (1) - el sujeto transitivo aparece antes del verbo en los siguientes casos: si es el primer constituyente de la oración que inicia una cláusula ${ }^{8}$ (Ell obispo Lucas lo cuenta assi / Los adeuinos cataron lo), si sigue directamente a un marcador discursivo (Así que un caçador armó sus lazos / Otrosí el omne entendido non debe poner su amor con ninguno...), y si es el primer constituyente después de un nexo coordinante (et la gulpeja oyó aquella boz) o subordinante (Dizen que un cuervo vio andar una perdiz / ca el fuerte viento non quebranta las chicas pajas).

La estructura revisada en este caso sugiere un sujeto transitivo con una elevada prominencia comunicativa, es decir, que constituye un tópico. Esto lo podemos corroborar revisando su continuidad referencial en el texto. Revisemos tres ejemplos de (1), apropiadamente contextualizados.

(i) - Señor, sepas que las naturalezas de las criaturas son de muchas maneras, et non es ninguna cosa de quantas Dio[s] crió en el

\footnotetext{
7 Sobre la distinción entre volitividad e intencionalidad, véase, entre otros, a Van Valin y Wilkins (1996: 313) y a Næss (2007: 39).

${ }^{8}$ La cláusula es, de acuerdo con Lope Blanch (1983: 53), una "expresión con autonomía elocutiva - mejor que sintáctica- derivada de su plenitud conceptual”.
} 
mundo, [...], más santa ni más mejor que el omne. Et en los omnes ha buenos et malos [...]

[...]

Otrosí el omne entendido ${ }_{i}$ non deve poner $\mathbf{s u}_{\mathrm{i}}$ amor con ninguno sinon después que $\emptyset_{\mathbf{i}}$ lo provare... (Calila, 316-317).

(ii) e ante quel yo pariesse, enuio el rey por los adeuinos de la tierra, e demando les daquello de que yo era prennada que auie de ser. Los adeuinos ${ }_{\mathrm{i}}$ cataron lo, e $\emptyset_{\mathrm{i}}$ uinieron al rey, e $\emptyset_{\mathrm{i}}$ dixieron le que nascerie de mi un fijo que semeiarie tan fuerte como fierro, e cruel, e que matarie a su padre (GE, 335, CCXXXV, 2, 15-20)

(iii) Dixo Dina: - Non ha fuerza nin valentía, ca yo me allegué a él et estude en par dél, así commo está ome con su igual. Et non me pudo fazer nada.

Dixo el león a Dina: - Non te engañe eso, nin lo tengas por flaco por eso, ca el fuerte viento ${ }_{i}$ non quebranta las chicas pajas, mas $\emptyset_{\mathrm{i}}$ desraiga los grandes árboles (Calila, 136)

En los tres casos resulta evidente la coherencia comunicativa de los sujetos transitivos considerados (el omne entendido, el fuerte viento y los adeuinos), tomando en cuenta, por un lado, que en el texto precedente presentan un antecedente nominal (en i y ii en cursiva) cuya base referencial es activada en el discurso subsecuente mediante su repetición en el núcleo nominal de la frase de sujeto (en negritas), ${ }^{9}$ y con el que funcionan como una forma de enlace textual (Silva-Corvalán, 1984: 6), o bien, presentan una descripción con la cual establecen continuidad temática (en iii) (Bogard, 2010a: 86), situación referencial que produce, en términos de Cooreman, coherencia anafórica. Y por otro lado, que en el texto subsecuente exhiben alguna forma que manifiesta la continuación temática (en (i) el posesivo su y la forma tácita $\emptyset$ del sujeto de provare, en (ii) el sujeto tácito de uinieron y dixieron, y en (iii) la forma tácita del sujeto de desraiga, persistencia temática que da por resultado coherencia ca-

\footnotetext{
${ }^{9}$ Sobre el concepto de activación referencial en el discurso, véase a Lambrecht (1994).
} 
tafórica ( $c f$. Cooreman, 1987: 13). El comportamiento descrito confirma la prominencia comunicativa de los sujetos transitivos antepuestos al verbo, y, en consecuencia, su estatus de tópicos.

De manera contrastante, en relación con el orden $\mathrm{VS}_{\mathrm{tr}}-\mathrm{los}$ ejemplos en (2) - , el sujeto transitivo tiende a ocupar la posición que inmediatamente sigue al verbo, y esto sucede en los siguientes casos: cuando la posición antepuesta al verbo es ocupada por un constituyente distinto del sujeto (et allí tenien los thebanos el mayor estudio de sos sacrificios e el mayor bollicio dellos / Por alguna cosa faze este mur lo que faze ), mismo caso de las oraciones transitivas inversas ${ }^{10}$ (et amas las encierra la mar de la una part), y del relativo de una oración adjetiva cuando desempeña la función de objeto directo (Agora contar uos emos por quel auenimiento contescio a aquel infante Acteon quel mataron los sos canes), o cuando el sujeto está formalizado mediante una estructura sintácticamente compleja (frases de sujeto coordinadas, o bien, con el núcleo nominal común expandido con una oración adjetiva o adnominal) (et lo entendieron sus ricos omnes et toda su compaña / et fázmela pedir el amor que te he).

El primer caso, es decir, cuando la posición que precede al verbo la ocupa un constituyente que no es el sujeto y, en consecuencia la frase que formaliza esta función se desplaza a la posición posverbal, nos sugiere que la posición preverbal no favorece la presencia de una estructura con dos constituyentes, uno de ellos el sujeto, como lo han mostrado para la oración intransitiva Alfonso y Melis (2010) y Melis y Alfonso (2013). Un tanto en esta línea, el segundo caso muestra que no es raro que constituyentes estructuralmente más complejos se sitúen a la derecha de su verbo, acorde con la tendencia expresada en un principio pragmático universal que señala que la información sintácticamente más densa se mueve al final de la oración (Payne, 1997: 326). ${ }^{11}$

\footnotetext{
${ }^{10}$ Sobre las oraciones transitivas inversas, véase a Givon (1994: 9), y sobre las transitivas inversas en español, a Bogard (2015: 19-20).

${ }^{11}$ Cf., a ese respecto, el concepto de dominancia en Greenberg (1966), y el principio de pesadez (heaviness principle) en Hawkins (1983).
} 
Revisemos ahora el comportamiento comunicativo de algunos ejemplos de (2).

(iv) En medio daquel mont Citheron, assi como cuenta la Estoria, auie un campo llano e no estaua en ell aruol ninguno, et assi estaua limpio de los aruoles e de toda mata que de toda part se ueye muy bien; et allí ${ }_{i}$ tenien los thebanos ${ }_{i}$ el mayor estudio de $\operatorname{sos}_{\mathbf{i}}$ sacrificios e el mayor bollicio dellos, et allí j estaua Agaue, madre desde infante Pentheo; e assi como entro por el mont adentro, nunqua quedo de andar, yendo al grant roydo que oye, fasta que uino $\underline{\text { a aquel campo }}_{\mathrm{j}}(G E, 191, \mathrm{LXVI}, 1,38-39 / 2,4-6)$

(v) Et mandaua este rey Busiris pensar destos huéspedes de guisa que los enbebdassen, et a los que enbebdar non podien que les dauan melecinas con que lo fuesen e se salliessen de sentido; desi tomauan los, e leuauan los a sos templos e a los logares o tenien sos ydolos, e degollaua los allí aquel rey ${ }_{\mathrm{i}}$ en sacrificio de $\mathbf{s o s}_{\mathrm{i} / \mathrm{j}}$ dioses, et $\emptyset_{\mathbf{i}}$ esparzie de la sangre por esos tiemplos e por esos logares (GE, 26, XI, 2, 3-10)

(vi) Et el religioso en este comedio sonando sus palmas a las vezes por me fazer fuir del canastillo, et ensañóse el huésped por ende et dixol': -Escarnio fazedes de mí, que me demandades que vos cuente nuevas et vós faziéndome esto.

Et escusósele el religioso, et díxole: - Grand sabor he de oír tus nuevas, mas fágolo por espantar unos mures que ha en esta casa que me fazen grand enojo, et nunca dexan cosa en el canastillo que me lo non coman et me lo royan.

Dixo el huésped: - ¿ Un mur es o muchos?

Dixo el religioso: - Los mures desta casa muchos son, mas ay uno que me ha fecho grand daño et non le puedo fazer ningund arte. Dixo el huésped: - Por alguna cosa faze este mur lo que $\emptyset_{i}$ faze; et miémbrome agora a lo que dixo un omne: - Por alguna cosa ca[n]bió esta muger el sínsamo descortezado por el por descortezar.

Dixo el religioso: —¿Cómmo fue eso? (Calila, 210-211)

(vii) Et quando Helbed esto oyó, non le mostró ningunt miedo, mas 
sonriósele en la cara, et díxole: - Señor, por esto non deves estar triste, ca nuestras almas ofresçidas te son, et de grado las dexaremos por librar a ti de tristeza et porque finques en tu regño. Et tú has otras mugeres sin mí, diez et seis mill con Jorfate, la bueña (sic) dueña que avrás en vez de mí; mas una cosa te quiero rogar et pedírtela en merçed, et fázmela pedir el gran amor que te he; que desque esto ovieres fecho non fíes nin creas por [los] Albahamiud, nin te aconseges nin creas por ellos en cosa del mundo, et que non mates a ninguno arrebatadamente, porque después non te arrepientas; ca non podrás resucitar al que matares (Calila, 285)

Lo primero que notamos en los ejemplos precedentes es un comportamiento no del todo uniforme en términos de la comunicación involucrada en los sujetos transitivos anotados en negritas. En dos casos, (v) y (vi), ambos sujetos, aquel rey y este mur, respectivamente, muestran coherencia comunicativa dado que los dos presentan un antecedente nominal (en cursiva) al que enlazan en una relación anafórica, y enseguida mantienen continuidad temática ( $\operatorname{sos}_{\mathbf{i}}, \boldsymbol{\emptyset}_{\mathbf{i}}$ y $\boldsymbol{\emptyset}_{\mathbf{i}}$, respectivamente). En otras palabras, se comportan como los sujetos transitivos antepuestos a su verbo cuyo núcleo nominal activa la referencia de los antecedentes con los cuales establecen una relación anafórica. En (iv), por su parte, el sujeto los thebanos no muestra un antecedente nominal con el que establezca continuidad temática, de modo que parece estar introduciendo su referencia en su contexto comunicativo. En este sentido estaría desempeñando la función informativa de foco en el sentido de Akmajian, ${ }^{12}$ con lo cual adquiere la posibilidad de proyectar coherencia catafórica, en este caso con el posesivo en negritas. En contraste, la forma allí, que inicia la oración transitiva con el sujeto pospuesto a su verbo, claramente establece la continuidad topical de la frase un campo llano, que continúa después con otro allí y termina con a aquel

\footnotetext{
${ }^{12}$ De acuerdo con Akmajian (1973: 218), el foco de una oración se define dentro de una relación semántica, y formaliza una información nueva no porque necesariamente lo sea, sino porque el tipo de relación semántica que contribuye a establecer es novedosa en un contexto discursivo específico.
} 
campo. Algo semejante sucede en (vi) con el complemento causal Por alguna cosa. Esta frase funciona como el disparador del recuerdo del huésped (miémbrome), y su continuidad temática se realiza mediante la repetición de la misma frase que establece la causa de una anécdota que recuerda el huésped, y que motiva al religioso a preguntar “¿cómmo fue eso?”. Finalmente en (vii) la oración transitiva con el sujeto pospuesto expresa un contenido temáticamente incidental y su sujeto, el gran amor que te he, carece de valor topical, en vista de que, en su contexto, ni se enlaza con un antecedente nominal ni presenta continuidad temática. Se pospone al verbo por su densidad sintáctica, puesto que su núcleo nominal está modificado por una oración adjetiva.

En conclusión, al comparar la estructura y el comportamiento comunicativo de los sujetos transitivos, hemos observado que los que se anteponen a su verbo se comportan de manera regular y estable, a diferencia de los que se le posponen, que exhiben comportamientos variables. Esto sugiere que, pese a mostrar una mayor frecuencia relativa, el orden $\mathrm{V}_{\text {tr }} \mathrm{S}$ resulta marcado en relación con el orden $S_{\mathrm{tr}}$, razón por la cual no es extraño que en los siglos subsecuentes se haya invertido la mayor productividad en favor de este último.

\subsection{Siglo XVI}

Revisemos los cuadros 5 para la información española, y 6 para la mexicana.

\begin{tabular}{|l|l|l|l|}
\hline S. XVI España & $\mathrm{S}_{\mathrm{tr}}-\mathrm{V}$ & $\mathrm{V}-\mathrm{S}_{\mathrm{tr}}$ & Total \\
\hline Núcleo nominal propio & $13(35.1 \%)$ & $24(64.9)$ & $37(100 \%)$ \\
\hline Núcleo nominal común & $51(62.2 \%)$ & $31(37.8 \%)$ & $82(100 \%)$ \\
\hline Total & $64(53.8 \%)$ & $55(46.2 \%)$ & $119(100 \%)$ \\
\hline
\end{tabular}

Cuadro 5. Sujeto transitivo siglo xvi, España: orden y tipo de núcleo nominal

\begin{tabular}{|l|l|l|l|}
\hline S. xvi México & $\mathrm{S}_{\mathrm{tr}}-\mathrm{V}$ & $\mathrm{V}-\mathrm{S}_{\mathrm{tr}}$ & Total \\
\hline Núcleo nominal propio & $5(83.3 \%)$ & $1(16.7 \%)$ & $6(100 \%)$ \\
\hline Núcleo nominal común & $54(72 \%)$ & $21(28 \%)$ & $75(100 \%)$ \\
\hline Total & $59(72.8 \%)$ & $22(27.2 \%)$ & $81(100 \%)$ \\
\hline
\end{tabular}

Cuadro 6. Sujeto transitivo siglo xvi, México: orden y tipo de núcleo nominal 
En total, el material procedente de los textos españoles nos ofrece 119 oraciones transitivas con sujeto explícito, y el material mexicano 81. Y en los textos de ambas variantes se observa que el orden $\mathrm{S}_{\mathrm{tr}} \mathrm{V}$ es el más productivo, aunque mucho más en la segunda mencionada. En efecto, los sujetos transitivos provenientes de los textos mexicanos aparecen en el 72.8\% (59/81) de los casos en el esquema $S_{\text {tr }} V$, y en el $27.2 \%$ restante $(22 / 81)$ en el esquema $\mathrm{VS}_{\mathrm{tr}}$, en tanto que los provenientes de los textos españoles lo hacen, en el 53.8\% de los casos (64/119) en el orden $\mathrm{S}_{\mathrm{tr}} \mathrm{V}$, y en el 46.2\% (55/119) en el orden $\mathrm{VS}_{\text {tr }}$. Y si bien, como decía, la tendencia entre los textos de ambas variantes favorece el orden con el sujeto transitivo antepuesto al verbo, la variante mexicana excede en 19 puntos porcentuales a la española. ${ }^{13}$

Me centraré ahora en los sujetos transitivos con núcleo nominal común, que son los que establecen la tendencia en el orden dominante $\mathrm{S}_{\mathrm{tr}} \mathrm{V}$ mencionada antes a propósito de los materiales del siglo xvi. Los textos revisados de ambas variantes muestran un predominio del sujeto transitivo antepuesto a su verbo. El material mexicano presenta el orden $\mathrm{S}_{\text {tr }} \mathrm{V}$ en una proporción del 72\% (54/75), en tanto que el español lo hace en una proporción del $62.2 \%$ (51/82). Y en ambos casos, como cabe esperar, la diferencia corresponde al orden $\mathrm{VS}_{\text {tr }}: 28 \%(21 / 75)$ en el material mexicano y $37.8 \%$ (31/82) en el español. Véanse, a continuación, algunos ejemplos con ambos órdenes, de la variante española en (3) y (5), y de la mexicana en (4) y (6):

\footnotetext{
${ }^{13}$ Esta diferencia tiene que ver con el distinto comportamiento que exhiben los textos de las dos variantes en lo tocante a los sujetos transitivos con núcleo nominal propio, pues mientras el material de los textos mexicanos apuntala la tendencia general mencionada al ostentar un $83.3 \%$ (5/6) de sujetos transitivos con este tipo de núcleo nominal antecediendo al verbo, el material de los textos españoles la atempera, dado que con núcleo nominal propio el sujeto transitivo se antepone al verbo en el $35.1 \%$ de las ocurrencias (13/37). Aquí habrá que mencionar que el comportamiento del material español está motivado por razones textuales, debido al uso del sustantivo Dios como nombre propio tanto en el Lazarillo de Tormes, como, y más aún, en Las moradas, que en total suma, en el material analizado, 9 ocurrencias como sujeto transitivo antepuesto al verbo, frente a 19 como sujeto transitivo pospuesto al verbo.
} 
$\mathrm{S}_{\mathrm{tr}}-\mathrm{V}$

(3)a. como el niño via a mi madre, y a mi blancos: y a el no huya del con miedo para mi madre $(L T, 5)$

entonces mi mujer echo juramentos sobre si, q yo pensé, la casa se hũdiera con nosotros, y despues tomose a llorar $(L T, 78)$ que anque un medio letrado, de los que tengo dichos, a quien preguntó cómo estaba Dios con nosotros [...], le dijo que no estaba más de por gracia (Moradas, 5, 1.89)

b. \& dixele, señor el buen aparejo haze buen artifice $(L T, 49)$ Creo fuera mejor no decir nada de las que faltan, pues no se ha de saber decir, ni el entendimiento lo sabe entender (Moradas, 5, 1.83)

la grandeza de Dios no tiene término (Moradas, 7, 1.217)

c. y assentoseme al lado y comiença a comer como aquel que lo auia gana royendo cada huessezillo de aqllos, mejor que vn galgo suyo lo hizera

$(L T, 49)$

(4)a. y que la causa prinçipal fue porque el gobernador abia demandado al señor de aquella çibdad oro y otras cosas (DLNE, 1525, 1.25)

porque demás que todos los españoles dessean passarse a una destas dos partes (DLNE, 1525, 1.44)

$\mathrm{Y}$ como los enemigos los vieron pasar, desampararon el albarrada y las azoteas (Cortés, 1522, 3.158)

b. aunque el mucho tiempo que avia que no se sabía dél, daba a creer fuesse muerto (DLNE, 1525, 1.25)

y los bergantines iban quemando alrededor de la ciudad todas las casas que podían (Cortés, 1522, 3.156)

$\mathrm{V}-\mathrm{S}_{\mathrm{tr}}$

(5)a. según las tienen puestas [a las mujeres] en esta costumbre aquellos hidalgos del lugar $(L T, 45)$ 
Apenas auia acauado su oracion el deuoto señor mio: quando el negro Alguazil cae de su estado \& da tan gran golpe en el suelo que la yglesia toda hizo resonar $(L T, 67)$

Y considerá que éste y muy mayor tenían algunos santos que cayeron en graves pecados (Moradas, 3, 1.38)

b. En este tiempo dio el relox la vna despues de medio dia $(L T, 38)$ mas a mi no me pone asco el sabor dello $(L T, 41)$

la grandeza de Dios no tiene término, tampoco le ternán sus obras (Moradas, $7,1.217$ )

(6)y con el fuego desbarataron los yndios a los christianos (DLNE, $1525,1.25)$

según que de todo harán más larga relación a vuestra majestad los procuradores que ahora van de esta Nueva España (Cortés, $1522,3.201$ )

y también las recibieron [las cartas] los oficiales de vuestra majestad que en mi compañía estaban (Cortés, 1526, 5.243)

Los ejemplos anteriores muestran que el sujeto transitivo, tanto antepuesto al verbo como pospuesto, se comporta en el siglo XVI como ya comenté que lo hace en el XIII. En efecto, el sujeto precede al verbo si inicia la cláusula (Y como los enemigos los vieron pasar), si sigue a un marcador discursivo (entonces mi mujer echo juramentos) y después de un nexo, coordinante (ni el entendimiento lo sabe entender) o subordinante (como el niño via a mi madre, y a mi blancos). Y se pospone si la posición antepuesta al verbo la ocupa un constituyente que no es el sujeto (En este tiempo dio el relox la vna despues de medio dia), o si se trata de un sujeto sintácticamente complejo (de todo harán más larga relación a vuestra majestad los procuradores que ahora van de esta Nueva España). Asumimos, como consecuencia, que este comportamiento paralelo entre los sujetos transitivos de ambos siglos refleja que su función comunicativa en el siglo XVI no es distinta de la observada en el XIII.

Si ahora comparamos los datos derivados de los materiales analizados de los siglos XIII y XVI, advertimos que entre ambos 
siglos la tendencia en el orden general entre el verbo y el sujeto transitivo ha cambiado, pues mientras en los textos del siglo XIII dominaba el orden $\mathrm{VS}_{\mathrm{tr}}$, en los del xVI, en ambas variantes, lo hace el orden $S_{t r} V$. Recordemos que este orden, pese a no haber sido el más productivo en el siglo xiII, ya constituía el no marcado, de modo que no resulta inesperado el cambio mencionado.

Revisemos a continuación la naturaleza léxica de los sujetos transitivos con núcleo nominal común en el siglo xvi. Para este efecto revísense los cuadros, 7 para la información correspondiente a España, y 8 para la tocante a México.

\begin{tabular}{|l|l|l|l|l|}
\hline $\begin{array}{l}\text { S. XVI } \\
\text { España }\end{array}$ & Humano & $\begin{array}{l}\text { Animado } \\
\text { no humano }\end{array}$ & Inanimado & Total \\
\hline $\mathrm{S}_{\mathrm{tr}}-\mathrm{V}$ & $42(82.3 \%)$ & $1(2 \%)$ & $8(15.7 \%)$ & $51(100 \%)$ \\
\hline $\mathrm{V}-\mathrm{S}_{\mathrm{tr}}$ & $25(80.6 \%)$ & - & $6(19.4 \%)$ & $31(100 \%)$ \\
\hline
\end{tabular}

Cuadro 7. Sujeto transitivo siglo xvi, España: naturaleza léxica del núcleo nominal común

\begin{tabular}{|l|l|l|l|l|}
\hline $\begin{array}{l}\text { S. XVI } \\
\text { México }\end{array}$ & Humano & $\begin{array}{l}\text { Animado } \\
\text { no humano }\end{array}$ & Inanimado & Total \\
\hline $\mathrm{S}_{\mathrm{tr}}-\mathrm{V}$ & $47(87 \%)$ & - & $7(13 \%)$ & $54(100 \%)$ \\
\hline $\mathrm{V}-\mathrm{S}_{\mathrm{tr}}$ & $21(100 \%)$ & - & - & $21(100 \%)$ \\
\hline
\end{tabular}

Cuadro 8. Sujeto transitivo siglo xvi, México: naturaleza léxica del núcleo nominal común

Observamos que los textos de las dos variantes se comportan de la misma manera. En términos de la colocación relativa del sujeto transitivo, e independientemente del orden, el referente humano domina abrumadoramente: para los textos españoles, en el esquema $\mathrm{S}_{\mathrm{tr}} \mathrm{V}$ corresponde al 82.3\% (42/51), en tanto que para los textos mexicanos corresponde al 87\% (47/54). Por su parte, en el esquema $\mathrm{VS}_{\mathrm{tr}}$, la referencia humana en los textos españoles alcanza el 80.6\% (25/31), y en los textos mexicanos el $100 \%(21 / 21)$. Resulta evidente que con los verbos transitivos la naturaleza léxica predominante de sus sujetos con núcleo nominal común es la humana, y que este tipo de referencia no es el factor que determina la alternancia entre los órdenes $\mathrm{S}_{\mathrm{tr}} \mathrm{V}$ y 
$\mathrm{VS}_{\mathrm{tr}}$, aunque sí parece estar incidiendo en relación con el orden dominante ya mencionado, es decir, $\mathrm{S}_{\mathrm{tr}} \mathrm{V}$.

\subsection{Siglo XIX}

A continuación revisemos los sujetos transitivos en el siglo XIX, a partir de la información presente en los cuadros 9 y 10.

\begin{tabular}{|l|l|l|l|}
\hline S. xIx España & $\mathrm{S}_{\mathrm{tr}}-\mathrm{V}$ & $\mathrm{V}-\mathrm{S}_{\mathrm{tr}}$ & Total \\
\hline Núcleo nominal propio & $42(76.4 \%)$ & $13(23.6 \%)$ & $55(100 \%)$ \\
\hline Núcleo nominal común & $50(83.3 \%)$ & $10(16.7 \%)$ & $60(100 \%)$ \\
\hline Total & $92(80 \%)$ & $23(20 \%)$ & $115(100 \%)$ \\
\hline
\end{tabular}

Cuadro 9. Sujeto transitivo siglo xıx, España: orden y tipo de núcleo nominal

\begin{tabular}{|l|l|l|l|}
\hline S. xIx México & $\mathrm{S}_{\mathrm{tr}}-\mathrm{V}$ & $\mathrm{V}-\mathrm{S}_{\mathrm{tr}}$ & Total \\
\hline Núcleo nominal propio & $30(96.8 \%)$ & $1(3.2 \%)$ & $31(100 \%)$ \\
\hline Núcleo nominal común & $96(89.7 \%)$ & $11(10.3 \%)$ & $107(100 \%)$ \\
\hline Total & $126(91.3 \%)$ & $12(8.7 \%)$ & $138(100 \%)$ \\
\hline
\end{tabular}

Cuadro 10. Sujeto transitivo siglo xıx, México: orden y tipo de núcleo nominal

El material de los textos de ambas variantes nos muestra que la tendencia observada en el siglo XVI, de que el orden de constituyentes más productivo, es decir, $\mathrm{S}_{\mathrm{tr}} \mathrm{V}$, se ha incrementado sustancialmente en el siglo XIX, tanto con sujetos transitivos con núcleo nominal propio como con núcleo nominal común. Vemos, efectivamente, que en el texto español el orden en cuestión aparece en el $80 \%$ de los casos (92/115), en tanto que en el mexicano lo hace en el 91.3\% (126/138). Si consideramos aquí la información respectiva correspondiente al siglo XVI, recordaremos que en ese siglo el orden con sujeto transitivo antepuesto al verbo en la variante española apenas había excedido el $50 \%$ (53.8\%), mientras que la mexicana ya había alcanzado el $72.8 \%$. Esto nos indica que entre los siglos XVI y xIx la tasa de crecimiento de la estructura $\mathrm{SV}_{\text {tr }}$ en la española fue mayor que en la mexicana, $\Delta 48.7 \%{ }^{14}$ por $\Delta 26.4 \%$, respectivamente, lo que tuvo por efecto que en este último siglo la diferencia entre ambas se

${ }^{14} \Delta=$ tasa de crecimiento. 
redujera de 19 puntos porcentuales a 11, con el resultado de que ya en el xix la estructura $S_{t r} V$ en la variante española alcanzó a la mexicana como la normal cuando el sujeto transitivo aparece formalizado mediante una frase nominal, sea con núcleo nominal común o propio, como puede apreciarse en los cuadros 9 y 10.

El comportamiento evolutivo descrito muestra, finalmente, a un siglo XIX que abre la entrada a un estado que, hacia finales del xx se observa ya consolidado, y que llevó a diversos autores a señalar que el español es una lengua SVO ( $c f$. Contreras, 1983; Silva-Corvalán, 1984; Bentivoglio y Weber, 1986; Brucart y Hernanz, 1987; y Ocampo, 1990; entre otros). ${ }^{15}$

Correlativamente, el orden $\mathrm{VS}_{\mathrm{tr}}$ se ha vuelto claramente marcado en el xIX al variar su productividad entre ambas variantes entre el $10.3 \%$ y el $16.7 \%$, salvo el caso del sujeto transitivo con núcleo nominal propio en la mexicana, que se ha marginalizado al alcanzar apenas el 3.2\%. Veamos, a continuación, ejemplos de ambas variantes con los dos órdenes involucrados en el análisis, en (7) y (9) del texto español y en (8) y (10) del mexicano. La revisión de dichos ejemplos nos muestra que las causas que determinan el orden que ocupa el sujeto transitivo respecto de su verbo corresponden a las mismas mencionadas en los siglos XIII y XVI.

\section{$\mathrm{S}-\mathrm{V}_{\mathrm{tr}}$}

(7)a. La nobleza vetustense opinó que muerto el perro no se acabase la rabia (La Regenta, 4, 186)

Muchas veces en el teatro, cuando todo el público fijaba la atención en el escenario, un espectador, Ronzal, desde la platea del proscenio clavaba la mirada en el elegante Mesía (La Regenta, 7, 279)

La doncella se comía con los ojos a la señora (La Regenta, 10, 369)

\footnotetext{
${ }^{15}$ Con la salvedad de que como el español es una lengua de sujeto opcional, el orden transitivo más frecuente no es SVO sino VO (cf. Bogard, 2010a: 73), lo que ha llevado a otros autores a expresar que más bien se trata de una lengua VO (cf. Givon, 1984: 210, Pottier, 1988: 4 y 6 y Melis et al., 2006: 39), que antepone el sujeto al verbo cuando dicha función se formaliza mediante una frase nominal explícita, o un pronombre personal tónico.
} 
b. la educación de aquella señorita de cuatro años exigía cuidados muy especiales (La Regenta, 4, 189)

La luna la miraba a ella con un ojo solo, metido el otro en el abismo (La Regenta, 10, 371)

La aparente cordialidad y la alegría expansiva de todos los presentes ocultaban un fondo de rencores y envidias (La Regenta, 13, 482)

(8)a. el muchacho le hacía tantos daños de todo género en la casa, que no compensaban con las utilidades (Bandidos, 13, 84)

el director alargó la copa al muchacho con un sobrante de vino Jerez (Bandidos, 27, 200)

Los tres curas revistieron en la sacristía sus ornamentos (Bandidos, 54, 451)

El practicante no quitaba los ojos de Mariana (Bandidos, 54, 454)

b. Un día, el menos pensado, un golpe de sangre al volver del paseo con el

Director de Aduana, acabó al robusto Lecuona (Bandidos, 13, 84)

El párrafo del periódico causó una reacción en el ánimo de Crisanto (Bandidos, 27, 196)

mas el percance del naufragio le había ocasionado el grandísimo bien de que Lamparilla le quitase este enemigo (Bandidos, 40, 330)

c. los dos gatos de la casa se sacaron entre tanto el asado que estaba ya dispuesto (Bandidos, 13, 85)

$\mathrm{V}_{\mathrm{tr}}-\mathrm{S}$

(9)a. Aconsejaron los médicos aires del campo y del mar para la niña (La Regenta, 4, 188)

Gran conflicto habian creado al gobierno, en opinión de todos los del corro, el alcalde presidente del Ayuntamiento y la viuda del marqués de Corujedo (La Regenta, 13, 479)

la chimenea, al amor de cuya lumbre leyera en otros días tantos folletines la señorita Anunciación Ozores, que en paz / descansa (La Regenta, 10, 368-369) 
b. Adquirió su poema formas concretas (La Regenta, 4, 191)

A Ronzal ya le echaban chispas los ojos montaraces (La Regenta, $7,276)$

Miró a la llama de la lámpara suspendida sobre la mesa... La ofendía aquella luz (La Regenta, 10, 370)

(10)a. y por este medio sabía el director la conducta de todos los individuos del Resguardo (Bandidos, 13, 83)

Se casará con amor o sin él, porque se lo manda su padre (Bandidos, 54, 450)

y la miró el obispo dulcemente, animándola y procurando calmarla (Bandidos, 54, 454)

b. Lo que se necesita en este país es atrevimiento, y lo demás lo da la fortuna (Bandidos, 27, 197)

¿Si tengo celos, si me exaspera su desdén, si suspiro y me pongo triste como un colegial que acaba de salir al mundo...? ¡Oh, no! (Bandidos, 54, 449)

Revisemos, a continuación, en los cuadros 11 y 12, la naturaleza léxica de los sujetos transitivos en los textos del siglo XIX.

\begin{tabular}{|l|l|l|l|l|}
\hline S. xix España & Humano & $\begin{array}{l}\text { Animado } \\
\text { no humano }\end{array}$ & Inanimado & Total \\
\hline $\mathrm{S}_{\mathrm{tr}}-\mathrm{V}$ & $33(66 \%)$ & - & $17(34 \%)$ & $50(100 \%)$ \\
\hline $\mathrm{V}-\mathrm{S}_{\mathrm{tr}}$ & $6(60 \%)$ & $1(10 \%)$ & $3(30 \%)$ & $10(100 \%)$ \\
\hline
\end{tabular}

Cuadro 11. Sujeto transitivo siglo xıx, España: naturaleza léxica del núcleo nominal común

\begin{tabular}{|l|l|l|l|l|}
\hline S. XIx México & Humano & $\begin{array}{l}\text { Animado } \\
\text { no humano }\end{array}$ & Inanimado & Total \\
\hline $\mathrm{S}_{\mathrm{tr}}-\mathrm{V}$ & $62(64.6 \%)$ & $3(3.1 \%)$ & $31(32.3 \% \%)$ & $96(100 \%)$ \\
\hline $\mathrm{V}-\mathrm{S}_{\mathrm{tr}}$ & $11(100 \%)$ & - & - & $11(100 \%)$ \\
\hline
\end{tabular}

Cuadro 12. Sujeto transitivo siglo XIx, México: naturaleza léxica del núcleo nominal común

A lo largo de la historia del fenómeno en estudio hemos podido observar que la referencia animada, y en particular hu- 
mana, ha sido característica del sujeto transitivo con núcleo nominal común, independientemente del orden que ocupe el $\mathrm{S}_{\mathrm{tr}}$ en relación con el verbo, y esto se ha mostrado así tanto en los textos revisados del siglo XIII como en los del siglo XVI para ambas variantes, en que su productividad nunca fue menor al $80 \%$.

En este contexto, los textos del siglo xix de ambas variantes muestran un cambio que tiene que ver no con la productividad de los órdenes en que se presenta el sujeto transitivo, sino con su referencia. Observamos, en efecto, un aumento en la productividad de los sujetos transitivos inanimados, que se mueve entre el 30\% y el 34\%, recordando que hasta el xvi no había llegado al 20\%. Dejo para otro momento la revisión de los verbos con la finalidad de analizar si el aumento mencionado está vinculado con algún tipo de extensión de su riqueza léxica.

\section{Sujetos intransitivos}

\subsection{Siglo XIII}

Revisemos ahora los sujetos intransitivos con la información del cuadro 13.

\begin{tabular}{|l|l|l|l|}
\hline S. XIII & $\mathrm{S}_{\text {intr }}-\mathrm{V}$ & $\mathrm{V}-\mathrm{S}_{\text {intr }}$ & Total \\
\hline Núcleo nominal propio & $14(31.1 \%)$ & $31(68.9)$ & $45(100 \%)$ \\
\hline Núcleo nominal común & $66(28.4 \%)$ & $166(71.6 \%)$ & $232(100 \%)$ \\
\hline Total & $80(28.9 \%)$ & $197(71.1 \%)$ & $277(100 \%)$ \\
\hline
\end{tabular}

Cuadro 13. Sujeto intransitivo siglo xIII: orden y tipo de núcleo nominal

Como se aprecia, en el material del siglo XIII aparece un total de 277 oraciones con sujeto intransitivo explícito, incluyendo tanto frases nominales con núcleo sustantivo propio como frases nominales con núcleo sustantivo común. En términos de esta distinción, el 16.2\% (45/277) exhibe el sujeto como FN con núcleo nominal propio, con referencia humana en su mayoría, así como dioses y el sustantivo Dios. El restante $83.8 \%(232 / 277)$ corresponde a la FN de sujeto intransitivo con núcleo nominal común. Nótese que la distribución entre sustantivos propios y 
comunes acentúa la tendencia ya mostrada por el sujeto transitivo en estas mismas circunstancias en favor del segundo tipo de sustantivo.

Examinemos a continuación el orden del sujeto intransitivo en relación con su verbo. En el caso de este tipo de sujeto con núcleo nominal propio, el $31 \%(14 / 45)$ va antes de su verbo, mientras que el 69\% (31/45) se le pospone. Prácticamente el mismo comportamiento hallamos para el sujeto intransitivo con núcleo nominal común: $28.4 \%$ (66/232) se le antepone y $71.6 \%$ $(166 / 232)$ aparece pospuesto. Comparando esta información con la correspondiente observada para los sujetos transitivos, el material revisado de los textos del siglo XIII muestra, para ambos tipos de sujeto, un comportamiento similar: el sujeto tiende a posponerse al verbo, si bien de manera más acusada en el caso del sujeto intransitivo tanto con núcleo nominal propio como con núcleo nominal común. Veamos algunos ejemplos.

$$
\mathrm{S}_{\text {intr }}-\mathrm{V}
$$

(11)a. o si sus / yguales fueron provados por buenos et ovieron mijoría dél en dinidat et en onra (Calila, 135-136)

ca tales omnes uenien ya estonces a las casas de los reyes (GE, 26, XI, 1, 29-30)

ca ell otra quarta hermana Semele, madre deste dios Libero padre mismo, muerta era ya como auemos contado (GE, 191, LXVI, 2, 31-34)

b. Dizen que una gulpeja fanbrienta pasó por un árbol (Calila, 135)

las serpientes cayeron a Yno e Athamant de suso (GE, 230, CX, 1, 22-23)

c. así commo escapan los omnes de la mar por las naves, et las naves escapan por los omnes (Calila, 269)

e otro dia uernemos aquí a esto mismo, ca el sol ua ya muy alto e la calentura es muy grant (GE, 150, XXII, 1, 19-21)

Et yr uos edes quando el uiento solano que uos aduxo se tornare en abrego (GE, 404, CCCXL, 2, 21-23) 


$$
\text { V - S }
$$

(12)a. Desí posó con él un huésped una noche, et çenaron amos (Calila, 210)

Pues que esto dixo Agaue, encendiosse a locura toda la otra compaña quando aquello oyeron (GE, 191/192, LXVI, 2, 39 / 1, 1-2) e fueron luego essora llegados .x.mill onbres de armas pora yr aquella lid (GE, 311, CXCVIII, 2, 36-38)

b. et allí cerca del árbol avía un gato ${ }^{16}$ (Calila, 268) e ueras tu otrossi, como rebudiara el toro (GE, 25, XI, 1, 32-33)

c. et estava un atanbor colgado del árbol; et movióse el viento et firiéronlo los ramos (Calila,135)

et quando lo tragare, atravesársele ha el estaca en la garganta et morrá (Calila, 350)

Andados diez e ocho annos de Aoth, juyz de Israhel, contescieron los fechos que las estorias e autores de los gentiles cuentan de Persseo (GE, 267, CLIV, 1, 20-23)

et leuantosse luego un fuego de la piedra que lo gasto todo (GE, 311, CXCVIII, 1, 5-7)

Revisaré ahora la naturaleza léxica de los núcleos nominales de los sujetos intransitivos. Como en el caso de los sujetos transitivos, con los intransitivos el sentido de los sustantivos propios no incide en el orden entre el verbo intransitivo y su sujeto, considerando que expresan el nombre de seres humanos (personajes históricos, míticos...), dioses y el sustantivo Dios, principalmente. Por otro lado, los sujetos intransitivos con núcleo nominal común, como se aprecia en el cuadro 14, muestran un comportamiento semejante con independencia de si se anteponen o posponen al verbo. Es decir, la referencia léxica del núcleo de estos sujetos nada sugiere con respecto a su comportamiento posicional, pues las respectivas distribuciones para cada posición son equivalentes.

\footnotetext{
${ }^{16}$ En tanto verbo que formaliza un predicado de existencia, analizo avía como intransitivo, y su argumento como sujeto.
} 


\begin{tabular}{|l|l|l|l|l|}
\hline S. XIII & Humano & $\begin{array}{l}\text { Animado } \\
\text { no humano }\end{array}$ & Inanimado & Total \\
\hline $\mathrm{S}_{\text {intr }}-\mathrm{V}$ & $23(34.8 \%)$ & $13(19.7 \%)$ & $30(45.5 \%)$ & $66(100 \%)$ \\
\hline $\mathrm{V}-\mathrm{S}_{\text {intr }}$ & $55(33.1 \%)$ & $39(23.5 \%)$ & $72(43.4 \%)$ & $166(100 \%)$ \\
\hline
\end{tabular}

Cuadro 14. Sujeto intransitivo siglo XIII:

naturaleza léxica del núcleo nominal común

Efectivamente, con el orden $\mathrm{S}_{\text {intr }} \mathrm{V}$ hay un 54.5\% (36/66) de sujetos animados, de los cuales 34.8\% (23/66) refieren a seres humanos y $19.7 \%(13 / 66)$ a no humanos; hay, finalmente, un $45.5 \%(30 / 66)$ de sujetos intransitivos con referencia inanimada. Y con el orden alternante $\mathrm{VS}_{\text {intr. }}$ aparece un 56.6\% (94/166) de sujetos animados, 33.1\% (55/166) con referencia humana y $23.5 \%(39 / 166)$ con referencia no humana; queda, por último, un $43.4 \%(72 / 166)$ de sujetos intransitivos con referencia inanimada.

Aquí es importante hacer notar, sin embargo, una diferencia entre ambos tipos de sujeto que tiene que ver con la tendencia del sentido léxico del sustantivo común que encabeza la frase de sujeto respectiva, independientemente de la posición que guarde con su verbo. Dependiendo de si se trata de sujeto transitivo o intransitivo, cambia la distribución porcentual de la referencia animada humana frente a la inanimada. Claramente los sujetos transitivos tienen mayor proporción de referentes humanos que los intransitivos, pues de 116 sujetos transitivos con núcleo nominal común, 57.7\% (67/116) refiere a entidades humanas o concebidas como tales, en tanto que de 232 sujetos intransitivos con núcleo nominal común, 33.6\% (78/232) tienen dicho tipo de referencia. Por su parte, los sujetos intransitivos tienen una mayor proporción de referentes inanimados que los transitivos, dado que de 232 sujetos intransitivos con núcleo nominal común, $44 \%(102 / 232)$ refiere a entidades inanimadas, mientras que $17.2 \%$ (20/116) de sujetos transitivos lo hace.

Esta distribución alternante que, en términos de su naturaleza léxica, muestran los sujetos transitivos y los intransitivos, no es, de hecho, del todo inesperada, si tomamos en cuenta, por un lado, que la mayor parte de los sujetos transitivos formaliza el argumento instigador, causa o agente, el cognoscente, el re- 
ceptor, el perceptor, el experimentante, el poseedor, etc., derivado del predicado verbal transitivo, argumento que típicamente se codifica en sustantivos que denotan seres humanos, como se pudo apreciar en los ejemplos exhibidos; y por otro lado, que los sujetos intransitivos que derivan de los verbos inacusativos, así como de los que provienen de predicados verbales pasivos, anticausativos, estativos y resultativos, que formalizan principalmente el tema, el paciente, el estímulo, se codifican con mayor frecuencia mediante sustantivos que denotan entidades inanimadas, como en los ejemplos expuestos a continuación, los de la serie (a) con el orden $\mathrm{VS}_{\text {intr }}$ y los de la serie (b) con el orden $\mathrm{S}_{\text {intr }} \mathrm{V}$.

Con verbos inacusativos:

(13)a. et descendie el termino dessa suert por el ual del can-/naueral (GE, 80 / 81, LV, 2, 32-33 / 1,1)

b. ca esto contesce por natura quando el sol ua mas alto en tod ell anno en los mayores días (GE, 150, XII, 1, 4-6)

Con verbos estativos:

(14)a. En medio daquel mont Citherion, assi como cuenta la Estoria, auie un cam-l

po llano e non estaua en ell aruol ninguno (GE, 191 / 192, LXVI, $1,38-39 / 2,1-2)$

b. quando la cabesça está bien, el cuerpo está bien (Calila, 284)

En construcciones pasivas:

(15)a. et fue destruxo ell altar, comol mando Dios (GE, 311, CXCVIII, $2,1-2)$

b. Señor, por esto non deves estar triste, ca nuestras almas ofresçidas te son (Calila, 285) 
En construcciones anticausativas:

(16)a. Quando el asno oyó decir de las asnas, moviosele su sabor (Calila, 261)

b. Et yr uos edes quando el uiento solano que uos aduxo se tornare en abrego (GE, 404, CCCXL, 2, 21-23)

En construcciones resultativas:

(17)et estava un atanbor colgado del árbol (Calila, 135)

El panorama presentado deja abierta la pregunta de qué factor determina la posición que toma el sujeto intransitivo en relación con su verbo. Los ejemplos exhibidos del siglo XIII no parecen sugerir respuestas claras y regulares. Por un lado, dicho tipo de sujeto, tanto antepuesto como pospuesto al verbo, puede aparecer en oración que inicia cláusula, en oración coordinada y en oración subordinada, como puede apreciarse en los ejemplos de (11) y (12). Por otro lado, el peso sintáctico no parece incidir en la posición del sujeto, puesto que observamos que dicha función la puede formalizar una oración compleja tanto si se antepone al verbo, como en (11c) (quando el uiento solano que uos aduxo se tornare en abrego), como si se pospone, como en (12c) (constescieron los fechos que las estorias e autores de los gentiles cuentan de Persseo). Finalmente, son raros los casos en los que la posposición del sujeto intransitivo coincide con el hecho de que la posición antepuesta está ocupada por una frase que cubre una función distinta del sujeto, como en (12a) (Desí posó con él un huésped una noche / e fueron luego essora llegados .x.mill onbres de armas).

Hay un factor, sin embargo, que parece operar como tendencia en los ejemplos mostrados, y tiene que ver con el tipo de información que se está transmitiendo en el discurso textual. Los sujetos intransitivos antepuestos al verbo funcionan de manera predominante como tópicos, en tanto que los pospuestos lo hacen como focos, es decir, como la parte de la estructura de 
la oración que no comparten en su intercambio comunicativo el emisor del discurso y su receptor ( $c f$. Lambrecht, 1994:43). Consideremos algunos ejemplos, de (viii) a (x) con el orden $\mathrm{S}_{\text {intr }} \mathrm{V}, \mathrm{y}$ de (xi) a (xiii) con el orden $\mathrm{VS}_{\text {intr }}$.

(viii) et dize la glosa sobresto en el noueno libro de Ouidio Mayor que fabla el desta razon, que este rey Busiris que a los estrannos e omnes buenos fazie matar, ca tales omnes ${ }_{i}$ uenien ya estonces a las casas de los reyes; de mas que diz que como eran en aquella sazon las tierras muy yermas aun, e las yentes pocas, e las pueblas chicas e ralas que estonces los mas que en tiendas uiuien, los que las auer podien, e que non auie y aun otras casas de prestar nin o los omnes ${ }_{i}$ se acogiesen si non las de los reyes, e que los omnes estrannos $_{\mathrm{i}}$ que andauan dunas tierras en otras, que allí se acogien buenos e malos, ca allí fallauan las mas uiandas que en otra parte de la tierra (GE, 26, XI, 1, 25-39 / 2, 1-3)

(ix) Et traye aquella Thisiphone, rauia muy mala del infierno, los braços rebueltos de serpientes, e tendio los alli, e sagudio la cabesça e sonaron las culuebras que tenie en ella; et las unas le yazien por los ombros, las otras le andauan esparzudas por los pechos, e siblauan e echauan uenino por las bocas, e sacauan las lenguas yradas; e empos esto, metio aquella Thesiphone la mano a su cabesça, e tiro dos serpientes de medio de los cabellos, e echo las apriessa con su mano enpoçonada contra Yno e contra

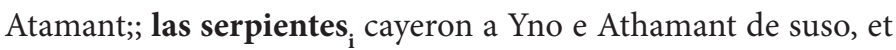
ellas $_{\text {i' }}$ o ell antoiança dellas , començaron les a andar por los cuellos, e por los pechos, e por los senos, e en derecho de los coraçones, e $\emptyset_{\mathrm{i}}$ metieron les muy malos talentes (GE, 230, CX, 1, 9-27)

(x) Et plégate desto, et ayúdame a librar a mí et a ti; ca así commo yo quiero tu vida por razón de la mía, otrosí tú deves amar mi vida por razón de la tuya, así commo escapan los omnes de la mar por las naves, et las naves escapan por los omnes. Et así fío yo por Dios que escaparemos desta tribulación, amos ayudándonos (Calila, 269) 
En estos tres casos, los sujetos intransitivos (tales omnes, las serpientes, las naves) constituyen tópicos en sus oraciones, y como mencionábamos a propósito de los sujetos transitivos tópicos, muestran, por un lado, coherencia anafórica, dado que presentan antecedentes nominales (en (viii) los estrannos e omnes buenos, en (ix) serpientes, las culuebras, las unas, las otras, dos serpientes, y en ( $\mathrm{x}$ ) las naves) $\mathrm{y}$, por otro, coherencia catafórica, la cual implica la continuidad del tema (en (viii) los omnes, los omnes estrannos, buenos $_{\mathrm{i}}$, malos $_{\mathrm{i}}$, en (ix) ellas, ellas $_{\mathrm{i}}, \emptyset_{\mathrm{i}} \mathrm{y}$ en (x) el uso del verbo 'escapar'.

(xi)Et traíanle cada día un canastillo de comeres, et comía dello una vez et dexava lo que fincava et colgávalo de una soga en un canastillo. Et yo açechávalo fasta que salía; desí veníame para el canastillo et non dexava ý cosa de que non comiese et que non echase a los otros mures. Et punó el religioso muchas veces de lo colgar en lugar que lo yo non pudiese alcançar, et non podía. Desí posó con él un huésped ${ }_{\mathrm{i}}$ una noche et çenaron $\mathbf{a m o s}_{\mathrm{j+i}}$; et estando fablando, dixo el religioso al huésped ${ }_{\mathrm{i}}:{ }_{i}$ De qué tierra eres $\emptyset_{\mathrm{i}}$ et a dó quieres $\emptyset_{\mathrm{i}}$ ir agora?

Et este su huésped $_{\mathrm{i}}$ avía andado a muchas partes et $\emptyset_{\mathrm{i}}$ avía visto maravillas, et $\emptyset_{\mathrm{i}}$ començól' a contar. (Calila, 210)

(xii) Dizen que en una tierra avía un árbol que llamavan vairod, et avía al pie dél muchos vestiblos, et en sus ramas muchos nidos de aves. Et avía a raíz deste árbol una cuerva de un mur, et allí çerca del árbol avía un gato [...]. Así que un caçador armó sus lazos et cayó ý el gato (Calila, 267-268)

(xiii) Andados diez e ocho annos de Aoth, juyz de Israhel, contescieron los fechos que las estorias e autores de los gentiles cuentan de Persseo, que fue después rey de Perssia, assi cuemo cuentan Eusebio e Jheronimo (GE, 267, CLIV, 1, 20-25)

De manera contrastante, en estos tres casos los sujetos intransitivos (un huésped, un gato, los fechos que las estorias e autores de los gentiles cuentan de Persseo) no presentan un an- 
tecedente nominal con el cual establezcan coherencia anafórica. Se trata de frases cuya referencia es nueva en el discurso; es del dominio del emisor de la comunicación, pero no es conocida por el receptor; en otras palabras, constituyen el foco de su oración. Sin embargo, a partir de que son presentadas en su oración adquieren la posibilidad de convertirse en objetos comunicativos. Puede observarse en (xi) y (xii) que el sujeto intransitivo es referencial indefinido (un huésped, un gato), pero una vez que se le "ha soltado" en el flujo de la comunicación adquiere el estatus de conocido y su referencia subsecuente aparece como definida.

\subsection{Siglo XVI}

Veamos ahora el estado de los sujetos intransitivos en los textos del siglo Xvi. Confróntense con este propósito el cuadro 15, que exhibe la información proveniente de los textos españoles, y el cuadro 16, que presenta la de los mexicanos.

\begin{tabular}{|l|c|l|l|}
\hline S. XVI España & $\mathrm{S}_{\text {intr }}-\mathrm{V}$ & $\mathrm{V}-\mathrm{S}_{\text {intr }}$ & Total \\
\hline Núcleo nominal propio & $6(37.5 \%)$ & $10(62.5 \%)$ & $16(100 \%)$ \\
\hline Núcleo nominal común & $69(36.7 \%)$ & $119(63.3 \%)$ & $188(100 \%)$ \\
\hline Total & $75(36.8 \%)$ & $129(63.2 \%)$ & $204(100 \%)$ \\
\hline
\end{tabular}

Cuadro 15. Sujeto intransitivo siglo Xvi, España: orden y tipo de núcleo nominal

\begin{tabular}{|l|r|r|r|}
\hline S. xvi México & \multicolumn{1}{|c|}{$\mathrm{S}_{\text {intr }}-\mathrm{V}$} & $\mathrm{V}-\mathrm{S}_{\text {intr }}$ & Total \\
\hline Núcleo nominal propio & $5(83.3 \%)$ & $1(16.7 \%)$ & $6(100 \%)$ \\
\hline Núcleo nominal común & $96(45.7 \%)$ & $114(54.3 \%)$ & $210(100 \%)$ \\
\hline Total & $101(46.8 \%)$ & $115(53.2 \%)$ & $216(100 \%)$ \\
\hline
\end{tabular}

Cuadro 16. Sujeto intransitivo siglo xvi, México: orden y tipo de núcleo nominal

En total, el material revisado de los textos españoles nos ofrece 204 oraciones intransitivas con sujeto explícito, y el procedente de los textos mexicanos 216. Y en los textos de ambas variantes el orden más productivo corresponde a $\mathrm{VS}_{\text {intr }}$, aunque de manera más acusada en el material peninsular. En efecto, en los textos de la variante española hallamos que el orden $\mathrm{VS}_{\text {intr }}$ apa- 
rece en el 63.2\% de los casos (129/204), frente al 36.8\% (75/204) con el orden $\mathrm{S}_{\text {intr }} \mathrm{V}$. Por su parte, en los textos mexicanos el orden $\mathrm{VS}_{\text {intr }}$ alcanza el 53.2\% de los casos (115/216) en contraste con el $46.8 \%(101 / 216)$ correspondiente al orden $\mathrm{S}_{\text {intr }}$ V. Se aprecia que, no obstante que la tendencia en los textos de ambas variantes favorece el orden en el que el sujeto intransitivo se pospone al verbo, la variante española lo hace en una proporción de 10 puntos porcentuales por encima de la mexicana, y, como en el caso del sujeto transitivo, la diferencia tiene que ver sustancialmente con el comportamiento de los sujetos intransitivos con núcleo nominal propio, pues en tanto que el material proveniente de los textos españoles refuerza la tendencia mencionada al mostrar un $62.5 \%(10 / 16)$ de sujetos intransitivos con núcleo nominal propio pospuestos al verbo, el material de los textos mexicanos muestra la tendencia opuesta con un $83.3 \%$ (5/6) de sujetos intransitivos con sustantivo propio precediendo al verbo. Aquí es llamativo el hecho de que siendo, en términos absolutos, pocos los sujetos intransitivos con núcleo nominal propio: 16 ocurrencias en el material de los textos españoles y 6 en el proveniente de los mexicanos, la elevada proporción de anteposición al verbo en este último caso es concomitante con el comportamiento ya observado y mencionado de que los sujetos transitivos de referencia humana en la variante mexicana tienden, más que en la española, al orden SV.

Revisaré ahora los sujetos intransitivos con núcleo nominal común, que, como en el caso de los sujetos transitivos, son los que establecen la tendencia en el orden más productivo, en este caso, $\mathrm{VS}_{\text {intr }}$ en lo tocante a los materiales analizados del siglo XVI. Los textos de las dos variantes exhiben una tendencia en la que el orden con el mayor rendimiento funcional presenta al sujeto intransitivo pospuesto al verbo. El material español presenta, para el orden $\mathrm{VS}_{\text {intr }}$, una proporción de uso del 63.3\% (119/188), en tanto que el mexicano lo hace del 54.3\% (114/210), con una productividad, para el orden $\mathrm{S}_{\text {intr }} \mathrm{V}$, del 36.7\% (69/188) en los textos españoles, y del $45.7 \%(96 / 210)$ en los mexicanos.

Comparemos ahora los datos derivados de los materiales de los siglos XIII y XVI revisados. Advertimos que, después de 
tres siglos de historia, el orden general dominante que observábamos para el siglo XIII, es decir, $\mathrm{VS}_{\text {intr }}$, se ha mantenido, aunque para el siglo XVI, su productividad ha disminuido, al pasar del $71.1 \%$ en el siglo XIII, al $63.2 \%$ en el XVI español y al 53.2\% en el XVI mexicano. Obsérvense algunos ejemplos con ambos órdenes, en (18) y (20) de la variante española, y en (19) y (21) de la mexicana.

$$
\mathbf{S}_{\text {intr }}-\mathbf{V}
$$

(18)a. acordaron el ayuntamiẽto que todos los pobres estrangeros se fuessen de la ciudad $(L T, 51)$

El señor Comissario se subio al pulpito, y comiença su sermón $(L T, 65)$

A todo esso el señor mi amo estaua en el pulpito de rodillas: las manos y los ojos puestos en el cielo trasportado* en la diuina essencia $(L T, 68)$

b. que estuue en poco de caer de mi estado no tãto de hambre como por conoscer d todo en todo la fortuna serme aduersa $(L T, 39)$ que si es verdad lo que aquel dize \& que yo traygo maldad y falsedad: este pulpito se hunda comigo (LT, 67)

Y este amor, hijas, no ha de ser fabricado en nuestra imaginación (Moradas, 3, 1.42)

ni las comparaciones pueden servir de declararlo, porque son muy bajas las cosas de la tierra para este fin (Moradas, 5, 1.83)

(19)a. mensajeros desta çibdad no podían passar sino que les matavan (DLNE, 1525, 1.24)

Y como el alguacil mayor comenzó a caminar, a obra de un cuarto de legua llegó a una ciudad pequeña (Cortes, 1522, 3.156)

Todos estos capitanes de estas entradas están ahora para partir casi a una (Cortés, 1526, 5.322)

b. y que decir [...] que esta çibdad está puesta en una laguna como Veneçia (DLNE, 1525, 1.43)

que habían dicho que otros dos navíos eran partidos para el río Pánuco (Cortés, 1522, 3.116) 
me llegaron otras cartas de ellos y de otras personas, en que me hacían saber cómo sus pasiones todavía duraban y aún crecían (Cortés, 1526, 5.244)

$\mathrm{V}-\mathrm{S}_{\text {intr }}$

(20)a. y al meter de las cosas y sacallas era con tanta vigilancia, y tan por cõtadero, q no bastara todo el mundo $\mathrm{a}^{*}$ hazerle menos vna migaja $(L T, 9)$

Quexauaseme el mal ciego porque al tiẽto luego conoscia y sentia q no era blanca entera $(L T, 10)$

ansí como lo quedó la mujer de Lod por volverla [la cabeza] (Moradas, 1, 1.9)

Parece que tiembla una criatura tan miserable como yo, de tratar en cosa tan ajena de lo que merezco entender (Moradas, 7 , $1.218)$

b. \& diome vna gran calabaçada en el diablo del Toro q mas de tres dias me duro el dolor de la cornada $(L T, 7)$

En tal manera q quisiera ser muerto antes q se me vuiera soltado aquella palabra de la boca $(L T, 78)$

y como no llegan sus fuerzas a esto, quédase espantado (Moradas, $5,1.85)$

(21)a. antes que llegaran a Cascalteche no quedara hombre dellos (DLNE, 1525, 1.43)

supe cómo dos provincias estaban rebeladas [...] y que como de la Vera Cruz para acá es por allí el camino, habían muerto en ellas algunos españoles (Cortés, 1522, 3.117)

porque cuando ellos habían ido, habian saltado ochenta hombres en un pueblo (Cortés, 1526, 5.281)

b. creyendo ya que eran hechos a la vela los navios que partieron de Medellin (DLNE, 1525, 1.24)

porque del puerto de Sanct Juan, donde agora vienen los navios, sube un braço de mar a este sitio donde agora se passa la dicha villa (DLNE, 1525, 1.33)

Y como yo vi que se me había revelado tan gran traición, di gracias a Nuestro Señor (Cortés, 1522, 3.199) 
y de este gran ayuntamiento de aguas que bajan de todas aquellas sierras se hacen aquellos golfos y ciénagas, y sale aquel río tan poderoso a la mar (Cortés, 1526, 5.283)

Los ejemplos anteriores, revisados en los textos fuente, muestran para el sujeto intransitivo del siglo XVI un comportamiento semejante al observado en el siglo XIII, a saber, el sujeto antepuesto al verbo normalmente funciona como el tópico de su oración, y el pospuesto lo hace como el foco respectivo. ${ }^{17} \mathrm{No}$ obstante, hay que mencionar que de los 13 ejemplos exhibidos con el orden $\mathrm{S}_{\text {intr }} \mathrm{V}, 4$ sujetos formalizan el foco y no el tópico (el primero de (18a), de (18b) y de (19a), y el segundo de (19b)). Anoto un par de ejemplos.

(xiv) Pues estando yo en tal estado, passando la vida que digo, quiso mi mala fortuna que de perseguirme no era satisfecha que en aquella trabajada y vergonçosa biuienda no durasse.

Y fue como el año en esta tierra fuesse esteril de pan, acordaron el ayuntamiẽto que todos los pobres estrangeros se fuessen de la ciudad.

Y assi executando la ley, desde a quatro días que el pregon se dio vi lleuar vna procession de pobres açotando por las quatro calles $(L T, 51)$

(xv) Asimismo hice saber a vuestra majestad cómo al puerto de la Villa de la Vera Cruz había llegado una carabela de Francisco de Garay, teniente de gobernador de la isla de Jamaica, con mucha necesidad; la cual traía hasta treinta hombres que habían dicho que otros dos navíos eran partidos para el río Pánuco, donde habían desbaratado a un capitán del dicho Francisco de Garay, y que temían que si allá aportasen habían de recibir daño de los naturales de dicho río (Cortés, 1522, 3.116)

\footnotetext{
${ }^{17}$ En el siglo XVI, igual que en el XIII, continúa siendo poco frecuente la estructura en la cual el sujeto intransitivo pospuesto a su verbo coincide con un constituyente distinto del sujeto en la posición preverbal, como el primer ejemplo de (20b) (q mas de tres días me duro el dolor de la cornada) y el segundo de (21b) (... donde agora vienen los navios, [...] donde agora se passa la dicha villa).
} 
En ambos casos los sujetos intransitivos en cuestión no presentan un antecedente nominal con cuya referencia establezcan coherencia anafórica.

Veamos, a continuación, la naturaleza léxica de los sujetos intransitivos encabezados por núcleo nominal común en el siglo XVI. El cuadro 17 exhibe la información del material español y el cuadro 18 la del mexicano.

\begin{tabular}{|l|l|l|l|l|}
\hline \multicolumn{1}{|c|}{ S. XVI España } & Humano & $\begin{array}{l}\text { Animado } \\
\text { no humano }\end{array}$ & Inanimado & Total \\
\hline $\mathrm{S}_{\text {intr }}-\mathrm{V}$ & $20(29 \%)$ & - & $49(71 \%)$ & $69(100 \%)$ \\
\hline $\mathrm{V}-\mathrm{S}_{\text {intr }}$ & $30(25.2 \%)$ & $2(1.7 \%)$ & $87(73.1 \%)$ & $119(100 \%)$ \\
\hline
\end{tabular}

Cuadro 17. Sujeto intransitivo siglo xvi, España:

naturaleza léxica del núcleo nominal común

\begin{tabular}{|l|l|l|l|l|}
\hline \multicolumn{1}{|c|}{ S. Xvi México } & Humano & $\begin{array}{l}\text { Animado } \\
\text { no humano }\end{array}$ & Inanimado & Total \\
\hline $\mathrm{S}_{\text {intr }}-\mathrm{V}$ & $49(51 \%)$ & - & $47(49 \%)$ & $96(100 \%)$ \\
\hline $\mathrm{V}-\mathrm{S}_{\text {intr }}$ & $32(28.1 \%)$ & - & $82(71.9 \%)$ & $114(100 \%)$ \\
\hline
\end{tabular}

Cuadro 18. Sujeto intransitivo siglo xvi, México:

naturaleza léxica del núcleo nominal común

Encuentro, en este caso, un doble comportamiento, que contribuye a explicar la mencionada distinta productividad del orden $\mathrm{VS}_{\text {intr }}$ observada entre los materiales de los textos españoles y mexicanos. Por un lado, el sujeto intransitivo pospuesto al verbo porta referencia inanimada de manera dominante en el material de ambas variantes: $73.1 \%(87 / 119)$ en la española y $71.9 \%$ (82/114) en la mexicana, frente al 25.2\% (30/119) de referencia humana en la española ${ }^{18}$ y $28.1 \%(32 / 114)$ en la mexicana. Por otro lado, el sujeto intransitivo antepuesto al verbo muestra un comportamiento doble. En el caso de los materiales españoles continúa dominando la referencia inanimada, con una productividad del 71\% (49/69), frente al 29\% (20/69) de referencia humana; en cambio los materiales mexicanos, si bien por escaso margen, invierten la proporción, al exhibir 51\% (49/96) de

\footnotetext{
${ }^{18} \mathrm{Y}$ un margen de $1.7 \%(2 / 119)$ de referencia animada no humana.
} 
sujetos intransitivos con núcleo nominal común con referencia humana y 49\% (47/96) con referencia inanimada. La información presentada en este párrafo nos muestra que con los verbos intransitivos la naturaleza léxica predominante de sus sujetos con núcleo nominal común es la inanimada, factor que, junto con su naturaleza focal, contribuye a explicar el correspondiente orden dominante $\mathrm{VS}_{\text {intr.' }}$, particularmente en la variante española. El atípico comportamiento de la variante mexicana en relación con la naturaleza léxica del sujeto intransitivo antepuesto al verbo sugiere, por su parte, la causa de por qué la productividad del orden dominante $\mathrm{VS}_{\text {intr }}$ aparece bastante atemperada en ella. La revisión de otros materiales, en este caso, permitirá confirmar o reformular el comportamiento aparentemente atípico mostrado por los materiales mexicanos.

\subsection{Siglo XIX}

Pasemos, finalmente, al examen de los sujetos intransitivos en los textos del siglo xix, cuya información exhibo en los cuadros 19 para el texto español, y 20 para el mexicano.

\begin{tabular}{|l|c|l|l|}
\hline S. XIx España & $\mathrm{S}_{\text {intr }}-\mathrm{V}$ & $\mathrm{V}-\mathrm{S}_{\text {intr }}$ & Total \\
\hline Núcleo nominal propio & $42(67.7 \%)$ & $20(32.3 \%)$ & $62(100 \%)$ \\
\hline Núcleo nominal común & $84(61.8 \%)$ & $52(38.2 \%)$ & $136(100 \%)$ \\
\hline Total & $126(63.6 \%)$ & $72(36.4 \%)$ & $198(100 \%)$ \\
\hline
\end{tabular}

Cuadro 19. Sujeto intransitivo siglo XIX, España: orden y tipo de núcleo nominal

\begin{tabular}{|l|c|l|l|}
\hline S. XIx México & $\mathrm{S}_{\text {intr }}-\mathrm{V}$ & $\mathrm{V}-\mathrm{S}_{\text {intr }}$ & Total \\
\hline Núcleo nominal propio & $23(71.9 \%)$ & $9(28.1 \%)$ & $32(100 \%)$ \\
\hline Núcleo nominal común & $125(60.4 \%)$ & $82(39.6 \%)$ & $207(100 \%)$ \\
\hline Total & $148(61.9 \%)$ & $91(38.1 \%)$ & $239(100 \%)$ \\
\hline
\end{tabular}

Cuadro 20. Sujeto intransitivo siglo xix, México: orden y tipo de núcleo nominal

Los materiales examinados del siglo XIII y los del XVI de ambas variantes mostraron para el sujeto intransitivo la tendencia a posponerse al verbo, aunque en una proporción des- 
cendente entre ambos siglos. El siglo XIX, por su parte, exhibe un panorama distinto. En efecto, los textos de las dos variantes presentan ya la tendencia inversa, es decir, en este siglo el sujeto intransitivo se antepone al verbo con más frecuencia de la que se pospone, y no incide en este comportamiento el hecho de que el sujeto tenga núcleo nominal común o propio. En relación con la productividad del orden $\mathrm{VS}_{\text {intr }}$ los textos de los tres siglos estudiados nos muestran el siguiente proceso de cambio: para la variante española, siglo xIII, 71.1\% > siglo XVI, $63.2 \%>$ siglo XIX, 36.4\%, y para la mexicana, siglo XVI, 53.2\% > siglo XIX, $38.1 \%$. Claramente, el rendimiento funcional del orden $\mathrm{VS}_{\text {intr }}$ ha ido disminuyendo a lo largo del tiempo hasta dejar de ser dominante en el siglo xIX. De manera contrastante, el orden $\mathrm{S}_{\text {intr }} \mathrm{V}$ en este mismo siglo acabó por convertirse en el dominante de acuerdo con el siguiente proceso de cambio: para la variante española, siglo xIII, 28.8\% > siglo XVI, 36.8\% > siglo xIX, 63.6\%, y para la mexicana, siglo xvi, $46.8 \%>$ siglo xIX, $61.9 \%$. Podemos suponer, por las proporciones de uso alcanzadas por los órdenes alternantes, que el proceso de cambio sigue en marcha y que continuará en la dirección de aumentar el dominio del sujeto intransitivo antepuesto al verbo, como ya lo hizo en el XIX el sujeto transitivo. ${ }^{19}$

\footnotetext{
${ }^{19}$ En su trabajo sobre la posición del sujeto intransitivo en español, con análisis de verbos tomados del Corpus de referencia del español actual (CREA, México, 1980-2006), Alfonso y Melis encuentran que el sujeto intransitivo se pospone al verbo menos de lo que se espera y afirma, y que, de hecho, el sujeto antepuesto es más frecuente (2010: 42). Incluso en el contraste entre su referencia animada e inanimada, observan que, si bien la referencia animada favorece la anteposición, la referencia inanimada muestra una ligera tendencia también a la anteposición (2010: 51). Su hallazgo crucial, sin embargo, lo constituye haber identificado el hecho de que la posición del modificador adverbial (al que representan como X) interviene en la determinación del orden del sujeto intransitivo, de modo que el esquema VX favorece el orden SVX, en tanto que el esquema XV favorece el orden XVS (2010: 60 y ss.). Un punto de vista semejante lo presenta Mora-Bustos desde un análisis de variación sincrónica de 108 entrevistas orales tomadas del Corpus sociolingüístico de la ciudad de México (Lastra y Martín Butragueño, 2000), quien señala, por un lado, que el sujeto preverbal es más frecuente que el posverbal (2014: 582) y, por otro, que hay una fuerte correlación entre la presencia y posición de un adjunto, antepuesto o
} 
Veamos a continuación ejemplos con ambos órdenes, en (22) y (24) del texto español, y en (23) y (25) del mexicano.

$$
\mathrm{S}_{\text {intr }}-\mathrm{V}
$$

(22)a. La familia de los Ozores era una de las más antiguas de Vetusta (La Regenta, 4, 184)

No faltaba para que la máquina fuese perfecta más que esto: que los ladrones de gallinas viniesen a tropezar con el botón del resorte endiablado (La Regenta, 10, 373)

Los tres canónigos se levantaron; la señora que parecía un fraile sonrió satisfecha (La Regenta, 13, 482)

b. pero así como la lista civil le dolía lo mismo que si él la pagase entera, de las mangas y capirotes que hacían con sus bienes le importaba poco (La Regenta, 4, 189)

La disputa se acaloró; tuvieron que intervenir los señores venerables del rincón oscuro (La Regenta, 7, 277)

Estas conversaciones se repetían todos los días (La Regenta, 7, 280)

El despacho estaba a oscuras; allí no entraba la luna (La Regenta, 10, 372)

El sol entraba en el salón amarillo (La Regenta, 13, 478)

c. Quintanar era correccionalista; quería la enmienda del culpable, pero no su destrucción. Los zorros que él cazara sobrevivirían (La Regenta, 10, 373)

(23)a. El dueño del mesón murió, y el nuevo dueño lo primero que hizo fue echar a los inquilinos (Bandidos, 13, 85)

los chalcas vinieron, como otras muchas tribus, de tan lejanas y tan ignoradas tierras (Bandidos, 40, 325)

Después del evangelio, el obispo subió al púlpito (Bandidos, 54, 453)

pospuesto al verbo, y la alternante posición del sujeto nominal o pronominal: sujetoverbo con verbo-adjunto y verbo-sujeto con adjunto-verbo (2014: 583). 
b. y no hay que decir, que los cien pesos habían ya volado (Bandidos, 13, 85)

Los crímenes deben perseguirse de oficio (Bandidos, 27, 196)

Un petate de Puebla con tejidos rojos servía de tapete al estrado (Bandidos, 40, 328)

c. y el perro ladraba todo el tiempo (Bandidos, 13, 85)

$\mathrm{V}-\mathrm{S}_{\text {intr }}$

(24)a. - Si viviera mi padre - pensaba Ozores- de fijo perdonaba este matrimonio desigual (La Regenta, 4, 185)

Miraba a Mesía Ronzal, y si aplaudía su modelo aborrecido aplaudía él (La Regenta, 7, 279)

Es loco ese chico, cuando se pone a enredar (La Regenta, 13, 481)

b. No le faltaba talento, era apasionado y se asimilaba con facilidad ideas que entendía muy pronto (La Regenta, 4, 187)

se quejaba de que se le había enfriado el café, que tomaba a pequeños sorbos (La Regenta, 7, 278)

El despacho estaba a oscuras; allí no entraba la luna (La Regenta, $10,372)$

Empezaron las despedidas, y los que se iban disimulaban el despecho (La Regenta, 13, 483)

(25)a. Morir Lecuona y ser puesto el hijo de patitas en la calle, todo fue uno (Bandidos, 13, 84)

Un día, antes de las ocho de la mañana entró el pilluelo sofocado, sin poder articular bien palabra (Bandidos, 27, 199)

y allí van también no pocos ladrones a ver lo que pescan (Bandidos, 40, 325)

b. y desde que amaneció el siguiente día comenzó con furor la obra (Bandidos, 13, 88)

Llegó la noche y con ella las sospechas, los comentarios y pláticas de las vecinas (Bandidos, 27, 200)

Añádase a esto la falta de muebles y de habitantes, y resultaba el caserón un tanto pavoroso (Bandidos, 40, 327) 
Le dolía no sólo el cuerpo sino el alma (Bandidos, 54,448)

Durante una semana no cesaron las fiestas (Bandidos, 54, 451)

Estos ejemplos, revisados en los textos de los que se tomaron, exhiben un comportamiento relativamente semejante al observado en los siglos XIII y XVI: el sujeto intransitivo topical tiende a colocarse antes de su verbo, en tanto que el que expresa el foco tiende a posponerse; los ejemplos muestran, sin embargo, que ha aumentado el número de sujetos intransitivos topicales pospuestos, lo mismo que el de focos antepuestos. Aunque por falta de espacio no anoto los contextos requeridos, ejemplos de tópicos pospuestos son el segundo y tercer ejemplos de (24a) (su modelo aborrecido / ese chico), el tercero de (24b) (la luna), el primero y segundo de (25a) (el hijo / el pilluelo), y en el tercer ejemplo de (25b), el sujeto de la segunda oración (el caserón). En contraste, ejemplos de focos antepuestos son el segundo de (22a) (los ladrones de gallinas), el primero de (22b) (la lista civil), el segundo y el tercero de (23b) (los crímenes / un petate de Puebla con tejidos rojos) y el de (23c) (el perro).

Es necesario resaltar, además, que en relación con los sujetos intransitivos topicales pospuestos, es en este siglo en el que aparecen casos con un constituyente no sujeto antepuesto al verbo, los cuales sugieren la pertinencia del hallazgo de Alfonso y Melis (2010), Melis y Alfonso (2013) y Mora-Bustos (2014) de que el sujeto intransitivo en español suele posponerse a su verbo si la posición antepuesta es ocupada por un constituyente que desempeña otra función, y, agrego yo, si no desempeña la función pragmática de foco, dado que su posición normal es la pospuesta. Revísese nuevamente la nota 17 . Veamos los ejemplos.

(xvi) sin pedir luz ni encenderla, alumbrada por la luna, atravesó algunas habitaciones buscando la escalera del parterre; pero al pasar cerca del despacho de Quintanar, cambió de propósito y se dijo: "Entraré ahí; ése debe de tener fósforos sobre la mesa [...] El despacho estaba a oscuras; allí no entraba la luna (La Regenta, $10,372)$ 
(xvii) ...había una familia que tenía dos hijos aprendices en una imprenta donde se publicaba El Eco, y uno de ellos, el más listo y vivaracho, era el encargado de llevar las pruebas al director, el cual, al devolvérselas preguntaba si había algo de nuevo en la imprenta o en la calle $[\ldots]$

[...] Un día, antes de las ocho de la mañana entró el pilluelo sofocado, $\sin \boldsymbol{\emptyset}_{\mathbf{i}}$ poder articular bien palabra y $\mathbf{s u}_{\mathbf{i}}$ fisonomía todavía demudada, con un rollo de pruebas en la mano, que $\emptyset_{\mathrm{i}}$ había guardado en $\mathbf{s u}_{\mathbf{i}}$ casa por habérsele $\mathbf{e}_{\mathrm{i}}$ hecho tarde en la noche (Bandidos, 13, 84)

Ambos ejemplos tienen como base un verbo que desempeña una función presentativa, ${ }^{20}$ la cual permite "introducir o reintroducir un referente en el discurso, típicamente en los casos en los que el hablante se proponer convertir ese sujeto en un tópico discursivo" (Melis y Alfonso, 2013: 137), o cuando se quiere "simplemente centrar la atención sobre la entidad que se pone en escena" (Hetzron, 1975, apud Melis y Alfonso, 2013: 137). Los complementos antepuestos al verbo corresponden a un locativo (xvi) y a un temporal (xvii), coincidiendo con la tendencia observada por ambas autoras de que son ésos los complementos que se anteponen al verbo de manera predominante (2013: 131-132), y de los que dicen que funcionan en las oraciones presentativas como 'vehículo' de la puesta en escena del sujeto oracional” (2013: 138). En los ejemplos presentados observamos la coherencia anafórica que permite activar la referencia del sujeto intransitivo en cuestión, en (xvi) (la luna), reintroducida para centrar la atención sobre ella, y en (xvii) (el pilluelo), reintroducida en vista de su valor topical, como lo atestigua la coherencia catafórica que establece la continuidad temática proyectada a partir de la frase cuya referencia se ha activado.

\footnotetext{
${ }^{20}$ La función presentativa tiene como meta introducir un participante con un alto valor remático (Contreras, 1983: 74-75), de modo que se le pueda activar pragmáticamente si en el desarrollo subsecuente del discurso adquiere prominencia comunicativa ( $c f$. Hetzron, 1975: 374; Du Bois, 1987: 831; Lambrecht, 1988: 149).
} 
Pasemos ahora a la revisión, en los cuadros 21 y 22, de la naturaleza léxica de los sujetos intransitivos con núcleo nominal común en los textos del siglo xIx.

\begin{tabular}{|l|l|l|l|l|}
\hline S. XIx España & Humano & $\begin{array}{l}\text { Animado } \\
\text { no humano }\end{array}$ & Inanimado & Total \\
\hline $\mathrm{S}_{\text {intr }}-\mathrm{V}$ & $31(36.9 \%)$ & $2(2.4 \%)$ & $51(60.7 \%)$ & $84(100 \%)$ \\
\hline $\mathrm{V}-\mathrm{S}_{\text {intr }}$ & $14(26.9 \%)$ & - & $38(73.1 \%)$ & $52(100 \%)$ \\
\hline
\end{tabular}

Cuadro 21. Sujeto intransitivo siglo XIX, España: naturaleza léxica del núcleo nominal común

\begin{tabular}{|l|l|l|l|l|}
\hline S. xix México & Humano & $\begin{array}{l}\text { Animado } \\
\text { no humano }\end{array}$ & Inanimado & Total \\
\hline $\mathrm{S}_{\text {intr }}-\mathrm{V}$ & $56(44.8 \%)$ & $1(0.8 \%)$ & $68(54.4 \%)$ & $125(100 \%)$ \\
\hline $\mathrm{V}-\mathrm{S}_{\text {intr }}$ & $25(30.5 \%)$ & $1(1.2 \%)$ & $56(68.3 \%)$ & $114(100 \%)$ \\
\hline
\end{tabular}

Cuadro 22. Sujeto intransitivo siglo xix, México: naturaleza léxica del núcleo nominal común

Con excepción de los textos del siglo xiı para ambos órdenes y de los mexicanos del siglo Xvi para el orden $\mathrm{S}_{\text {intr }} \mathrm{V}$, en que la referencia inanimada se mantuvo por abajo del $50 \%$ de productividad, en el xIII con el orden $\mathrm{S}_{\text {intr }} \mathrm{V} 45.5 \%$, y con el orden $\mathrm{VS}_{\text {intr }}$ $43.4 \%$, y en el XVI mexicano $49 \%$ para el orden $\mathrm{S}_{\text {intr }} \mathrm{V}$, la referencia más frecuente para el sujeto intransitivo con núcleo nominal común ha sido la inanimada, moviéndose para el orden $\mathrm{VS}_{\text {intr }}$ entre el $68.3 \%$ y el $73.1 \%$, y para el orden $\mathrm{S}_{\text {intr }} \mathrm{V}$ entre el $54.4 \%$ y el $60.7 \%$. Se puede advertir, en consecuencia, que aunque es dominante, no constituye regla.

Ahora bien, en los textos del XIII y los del XVI para ambas variantes el orden más frecuente de los sujetos intransitivos es pospuesto al verbo, lo cual podría correlacionarse con su también más frecuente referencia inanimada, tomando en consideración que este tipo de referencia es la normal para la función de objeto directo, que históricamente se ha pospuesto al verbo transitivo en una proporción muy elevada. Los textos del xIX, sin embargo, muestran, como cambio evidente, la ruptura de dicha correlación, dado que, manteniéndose como más productiva la referencia inanimada, el orden más frecuente ha pasado a ser 
$\mathrm{S}_{\text {intr }} \mathrm{V}$, hecho que parece sugerir que el orden de constituyentes en español, al menos cuando el sujeto es intransitivo, ha perdido sensibilidad a la referencia como motivador del orden estructural, en beneficio de la percepción de la función sintáctica.

\section{Conclusión}

Los textos objeto del análisis muestran tanto para el sujeto transitivo como para el intransitivo un comportamiento posicional semejante en cada siglo, es decir, sincrónicamente, aunque cambiante a lo largo del periodo estudiado, hasta llegar al siglo XIX, que prefigura el estado observable a finales del xx y principios del Xxi. Observamos en los textos del siglo xiII que el sujeto tiende a posponerse al verbo, aunque en una mayor proporción en el caso del sujeto intransitivo. Asimismo resultó claro que los sujetos transitivos presentan una mayor proporción de referentes humanos que los sujetos intransitivos, los cuales, por su parte, muestran una mayor frecuencia de referentes inanimados. Este comportamiento alternante no resulta extraño dado que mientras la mayoría de los sujetos transitivos codifica el argumento instigador, causa o agente, el cognoscente, el receptor, el perceptor, el experimentante, el poseedor, etc., derivados del predicado verbal, la mayoría de los sujetos intransitivos formaliza principalmente el tema, el paciente, el estímulo, argumentos provenientes de predicados inacusativos o de predicados verbales pasivos, anticausativos, estativos y resultativos.

Teniendo como punto de referencia el comportamiento de ambos tipos de sujetos en el siglo XIII, los textos del XVI nos muestran un comportamiento diferente. En el caso de los sujetos transitivos, el orden más frecuente ha pasado a ser $\mathrm{S}_{\mathrm{tr}} \mathrm{V}, \mathrm{y}$ aunque la naturaleza léxica dominante de este tipo de sujeto es la humana, no es el factor que establece la diferencia entre los dos órdenes alternantes, si bien sí parece incidir en el aumento de la proporción de sujetos transitivos antepuestos al verbo. Por otra parte, y en relación con los sujetos intransitivos, aún prevalece el orden $\mathrm{VS}_{\text {intr }}$, aunque con un rendimiento funcional disminui- 
do en relación con el observado en el siglo xiII. En este caso, la naturaleza léxica dominante de los sujetos intransitivos, la inanimada, nos sugiere una explicación posible al más lento avance observado en la disminución de la productividad del orden con el sujeto respectivo pospuesto al verbo. Por último, en relación con el análisis de los textos del siglo xvi, la proporción de los sujetos transitivos antepuestos al verbo es mayor en la variante novohispana que en la española (sólo con sustantivos comunes $72 \%$ frente a $62.2 \%$, respectivamente, e incluyendo también los sustantivos propios, $72.8 \%$ frente a $53.8 \%$ ), en tanto que la frecuencia proporcional de los sujetos intransitivos pospuestos al verbo es mayor en los textos de la variante española que en los de la novohispana (sólo con sustantivos comunes 63.3\% frente a $54.3 \%$, respectivamente, e incluyendo también los propios, $63.2 \%$ frente a 53.2\%). Este estado de cosas exhibe una variante novohispana más distante que la española en relación con el tipo de estructura observada en el siglo xIII, y que apunta en dirección al estado más frecuente del xix y el vigente a fines del xx y principios del XxI.

En efecto, los textos del XIX, en relación con el sujeto transitivo, muestran que el español presenta $80 \%$ de sujetos antepuestos al verbo ( $76.4 \%$ con sustantivos propios y $83.3 \%$ con sustantivos comunes), en tanto que la proporción del mexicano es de $91.3 \%$ (96.8\% con sustantivos propios y $89.7 \%$ con sustantivos comunes). Al comparar esta información con la correspondiente del siglo XVI, queda claro que ambas variantes se dirigen a generalizar la estructura con el sujeto transitivo antepuesto al verbo, la española con una tasa de crecimiento entre ambos siglos de $48.7 \%$ y la mexicana, de $26.4 \%$. Correlativamente, la productividad de la estructura $\mathrm{VS}_{\mathrm{tr}}$ muestra un evidente retroceso al pasar, la variante española, al 20\%, y desplomarse la mexicana al alcanzar el 8.7\%; y esto ha sucedido no obstante que los textos de ambas variantes exhiben un aumento de poco más de $50 \%$ en la proporción de sujetos transitivos inanimados. Por otra parte, y en lo que atañe a los sujetos intransitivos, el cambio entre el siglo XVI y el XIX es más drástico, pues en este último la productividad entre ambos órdenes se ha invertido en las dos variantes, 
de modo que aparece como más productivo el orden $\mathrm{S}_{\text {intr }} \mathrm{V}$, en el caso de la española al pasar de $36.8 \%$ a $63.6 \%$, respectivamente, y en el de la mexicana $46.8 \%$ a $61.9 \%$, unificándose ambos tipos de sujeto en una sola estructura como la más productiva, a saber, con el sujeto antes del verbo, y apuntar al estado actual de la lengua, en el que la regla es que el sujeto antecede al verbo con independencia de si éste es transitivo o intransitivo.

Finalmente, el estado de cosas descrito en el párrafo precedente nos pone de frente a un siglo xix en el que ya no existen reglas distintas a propósito de las productividades alternantes en relación con los órdenes $\mathrm{S}_{\mathrm{tr}} \mathrm{V} / \mathrm{VS}_{\mathrm{tr}} \mathrm{y} \mathrm{S}_{\text {intr }} \mathrm{V} / \mathrm{VS}_{\text {intr. }}$. La alternancia existe en el XIX, como continúa existiendo a principios del XXI, pero es en el estado sincrónico del xIX en el que los textos nos muestran el punto de partida unificado del orden que hoy es claramente la regla: el sujeto antecede al verbo en español. En efecto, en el xix la productividad mínima del sujeto antepuesto al verbo, transitivo o intransitivo, excede el 60\%. Este comportamiento nos proporciona un nuevo argumento en favor de asumir dicho siglo como el momento de inicio de una tercera etapa evolutiva en la historia del español.

\section{Corpus bibliográfico}

Calila: Anónimo, Calila e Dimna, edición de Juan Manuel Cacho Blecua y María Jesús Lacarra, Madrid, Castalia, 1984.

GE: Alfonso X, General estoria. Segunda parte, 2 vols., edición de Antonio G. Solalinde, Lloyd A. Kasten y Victor R. B. Oelschläger, Madrid, Consejo Superior de Investigaciones Científicas, 1957.

LT: Anónimo, Tri-linear edition of Lazarillo de Tormes of 1554 (Burgos, Alcalá de Henares, Amberes), edición de Joseph V. Ricapito, Madison, The Hispanic Seminary of Medieval Studies, 1987.

Cortés: Hernán Cortés, Cartas de relación, en Cartas y documentos, edición de Mario Hernández Sánchez-Barba, México, Porrúa, 1963. 
Moradas: Santa Teresa, Las moradas, edición de Tomás Navarro Tomás, Madrid, Espasa Calpe, 1951.

Regenta: Leopoldo Alas “Clarín”, La Regenta, 2 vols., edición de Gonzalo Sobejano, Madrid, Castalia, 1981.

Bandidos: Manuel Payno, Los bandidos de Río Frío, 2 vols., edición de Josefina Zoraida Vázquez, México, Clásicos de la Literatura Mexicana, 1979.

DLNE: Concepción Company Company, Documentos lingüísticos de la Nueva España. Altiplano-central, México, Universidad Nacional Autónoma de México, 1994.

\section{Bibliografía}

Alfonso Vega, M. y C. Melis (2010), “La posición del sujeto en la oración intransitiva del español", en S. Bogard (ed.), Semántica, pragmática y prosodia. Reflejos en el orden de palabras en español, México, El Colegio de México, pp. 39- 68. Akmajian, A. (1973), "The role of focus in the interpretation of anaphoric expressions", en S. R. Anderson y P. Kiparsky (eds.), A Festschrift for Morris Halle, Nueva York, Holt, Rinehart and Winston, pp. 215-226.

Bello, A. (1945), Gramática de la lengua castellana, Buenos Aires, Sopena (1a. ed. con notas de Rufino J. Cuervo, 1847).

Bentivoglio, P. y E. G. Weber (1986), "A functional approach to subject word order in spoken Spanish", en O. Jaeggli y C. Silva-Corvalán (eds.), Studies in Romance linguistics, Dordrecht, Foris, pp. 3-40.

Bogard, S. (2015), "Los clíticos pronominales del español. Estructura y función”, Nueva Revista de Filología Hispánica, 63, pp. 1-38.

Bogard, S. (2010a), "La frase nominal de objeto directo antepuesta al verbo en español”, en S. Bogard (ed.), Semántica, pragmática y prosodia. Reflejos en el orden de palabras en español, México, El Colegio de México, pp. 69-115.

Bogard, S. (2010b), "Del choque intercultural a la génesis del español novohispano", en R. Barriga Villanueva y P. Martín 
Butragueño (dirs.), Historia sociolingüística de México, vol. 1, México, El Colegio de México, pp. 207-286.

Bogard, S. (2009), "La frase nominal con núcleo sustantivo común", en C. Company Company (dir.), Sintaxis histórica de la lengua española. Segunda parte: La frase nominal, vol. 1, México, Universidad Nacional Autónoma de México / Fondo de Cultura Económica, pp. 57-268.

Bosque, I. (1999), I. “El nombre común”, en I. Bosque y V. Demonte (dirs.), Gramática descriptiva de la lengua española, vol. 1: Sintaxis básica de las clases de palabras, Madrid, Espasa, pp. 3-75.

Brucart, J. Ma. y Ma. Ll. Hernanz (1987), La sintaxis, Barcelona, Crítica.

Cano Aguilar, R. (1988), El español a través de los tiempos, Madrid, Arco Libros.

Company Company, C. (2009), "Estructura general de la frase nominal en el español alfonsí. Esbozo de diacronía”, en C. Company Company (dir.), Sintaxis histórica de la lengua española. Segunda parte: La frase nominal, vol. 1, México, Universidad Nacional Autónoma de México / Fondo de Cultura Económica, pp. 3-56.

Contreras, H. (1983), El orden de palabras en español, Madrid, Cátedra.

Cooreman, A. (1987), Transitivity and discourse continuity in Chamorro narratives, Berlín / Nueva York / Ámsterdam, Mouton de Gruyter.

Cruse, D. A. (1973), "Some thoughts on agentivity", Journal of Linguistics, 9:1, pp. 11-23.

Du BoIs, J. W. (1987), "The discourse basis of ergativity”, Language, 63:4, pp. 805-855.

Fernández Leborans, Ma. J. (1999), "El nombre propio”, en I. Bosque y V. Demonte (dirs.), Gramática descriptiva de la lengua española, vol. 1: Sintaxis básica de las clases de palabras, Madrid, Espasa, pp. 77-128.

Fernández-Ordóñez, I. (2008), "Alfonso X el Sabio en la historia del español”, en R. Cano Aguilar (coord.), Historia de 
la lengua española, $3^{\text {a }}$ reimpr., Barcelona, Ariel, pp. 381422 (1 a ed., 2004).

Givon, T. (1994), “The pragmatics of de-transitive voice. Functional and typological aspects of inversión", en T. Givon (ed.), Voice and inversión, Ámsterdam / Filadelfia, John Benjamins, pp. 3-44.

Givon, T. (1984), Syntax. A functional-typological introduction, vol. 1, Ámsterdam / Filadelfia, John Benjamins.

Givon, T. (1976), "Topic, pronoun and grammatical agreement", en C. Li (ed.), Subject and topic, Nueva York, Academic Press, pp. 25-55.

Greenberg, J. H. (1966), "Some universals of grammar with particular reference to tbe order of meaningful elements", en J. H. Greenberg (ed.), Universals of grammar, 2a ed., Cambridge, MS, MIT Press, pp. 73-113.

Hawkins, J. (1983), Word order universals, Nueva York, Academic Press.

Hetzron, R. (1975), “The presentative movement, or why the ideal order is V.S.O.P.", en C. Li (ed.), Word order and word order change, Austin, University of Texas Press, pp. 345-388. LAMBRECHT, K. (1994), Information structure and sentence form. Topic, focus and the mental representations of discourse referents, Cambridge, Cambridge University Press.

Lambrecht, K. (1988), "Presentational cleft constructions in spoken French", en J. Haiman y S. Thompson (eds.), Clause combining in grammar and discourse, Ámsterdam, John Benjamins, pp. 135-179.

LApesa, R. (1981), Historia de la lengua española, 9a ed., Madrid, Gredos.

Lope Blanch, J. M. (1983), Análisis gramatical del discurso, México, Universidad Nacional Autónoma de México.

Maldonado, R. (1999), A media voz. Problemas conceptuales del clítico se, México, Universidad Nacional Autónoma de México.

Melis, C. y M. Alfonso Vega (2013), "Circunstantes, sujetos y orden de palabras en la oración intransitiva del español", Lingüística, 29:2, pp. 127-151. 
Melis, C. (2012), "Precisiones lingüísticas en torno al concepto de agente", en R. E. González y A. Enríquez Ovando (coords.), Estudios sobre lengua y literatura, Morelia, Universidad Michoacana de San Nicolás de Hidalgo, pp. 15-40.

Melis, C., Y. Aguilar Gil, A. Aguilar Guevara y J. Araiza Tokumasu (2006), "Nueva evidencia en favor del tercer período evolutivo del español: el orden de palabras", Signos Lingüísticos, 3, pp. 33-67.

Melis, C., M. Flores Cervantes y S. Bogard (2003), "La historia del español: propuesta de un tercer período evolutivo", Nueva Revista de Filología Hispánica, 51:1, pp. 1-56.

Mora-Bustos, A. (2014), "Verbos intransitivos y adjuntos: un estudio multivariable", en P. Martín Butragueño y L. Orozco (eds.), Argumentos cuantitativos y cualitativos en sociolingüística (Segundo Coloquio de Cambio y Variación Lingüística), México, El Colegio de México, pp. 567-594.

NÆss, Å. (2007), Prototypical transitivity, Ámsterdam / Filadelfia, John Benjamins.

OcAmpo, F. (1990), "The pragmatics of word order in constructions with a verb and a subject", Hispanic Linguistics, 4, pp. 87-128.

Payne, T. E. (1997), Describing morphosyntax. A guide for field linguistics, Cambridge, Cambridge University Press.

Penny, R. (1993), Gramática histórica del español, Barcelona, Ariel.

Pottier, B. (1988), “¿Es el español una lengua S-V-O?”, Nueva Revista de Filología Hispánica, 36:1, pp. 3-7.

Ramchand, G. C. (2008), Verb meaning and the lexicon. A first -phase syntax, Nueva York, Cambridge University Press.

Real Academia Española y Asociación de Academias de la Lengua Española (2010), Nueva gramática de la lengua española. Manual, México, Real Academia Española / Asociación de Academias de la Lengua Española/Espasa/ Planeta Mexicana.

Silva-Corvalán, C. (1984), “Topicalización y pragmática en español”, Revista Española de Lingüística, 14:1, pp. 1-19.

VAn VAlin, JR., R. D. y D. P. Wilkins (1996), “The case for 'effec- 
tor': case roles, agents, and agency revisited", en M. Shibatani y S. A. Thompson (eds.), Grammatical constructions. Their form and meaning, Oxford, Oxford University Press, pp. 289-322.

Sergio Bogard. Profesor-investigador de tiempo completo del Centro de Estudios Lingüísticos y Literarios de El Colegio de México desde el 1 de mayo de 2002, es Licenciado en Lengua y Literaturas Hispánicas, egresado de la Facultad de Filosofía y Letras de la Universidad Nacional Autónoma de México, y Doctor en Lingüística por El Colegio de México, generación 1987-1990, donde obtuvo el grado con la tesis Hacia una gramática de los verbos psicológicos del español.

Su área de especialidad es la Gramática del español, tanto sincrónica como diacrónica (historia interna y externa), desde una perspectiva teórica funcional.

Comprometido con la enseñanza, ha desarrollado su labor docente principalmente en la Licenciatura en Lingüística de la Escuela Nacional de Antropología e Historia, institución en la que trabajó como profesor de tiempo completo de 1991 a 2002, y en el Doctorado en Lingüística y en la Maestría en Traducción de El Colegio de México. Colaboró también en la Licenciatura en Lingüística de la Universidad Autónoma Metropolitana-Iztapalapa, y en la Licenciatura en Lengua y Literaturas Hispánicas de la Universidad Nacional Autónoma de México. Ha sido profesor de la Maestría en Lingüística de la ENAH, de la Universidad de Sonora y de la Universidad de Querétaro, de la Maestría en Lingüística Hispánica de la UNAM, de la Maestría en Lingüística Indoamericana del Centro de Investigaciones y Estudios Superiores en Antropología Social, y de la Maestría en Lingüística Aplicada de la Universidad de Guadalajara. Y ha colaborado también en el Doctorado en Ciencias del Lenguaje de la ENAH, en el Doctorado en Lingüística de la UNAM y en el Doctorado en Antropología del CIESAS.

Como resultado de ese trabajo docente, ha dirigido 26 tesis, 9 de licenciatura (ENAH y UNAM), 8 de maestría (ENAH, CIESAS y UNAM) y 9 de doctorado (El Colegio de 
México, ENAH y Universidad Nacional del Nordeste, en Resistencia, Argentina), y ha sido tutor externo en más de una docena de tesis de maestría y doctorado de la UNAM y de la Universidad de Sonora.

En el ámbito de la investigación, ha publicado alrededor de 40 artículos y capítulos, y ha editado en El Colegio de México los libros Semántica, pragmática y prosodia. Reflejos en el orden de palabras en español, Del léxico al discurso. La construcción gramatical del sentido en español y Sentido y gramática en español. Entre sus artículos están, sobre el español actual, "Oraciones de complemento en español. Tipos, estructura y función", "Los clíticos pronominales del español. Estructura y función", "Actividad, atelicidad y 'pseudo-objeto' en español", "Aspecto, Aktionsart y transitividad en español", "Duplicación y clausura argumental: dos funciones del clítico reflexivo en español" y "Construcciones antipasivas en español"; y sobre historia interna, "Evolución de la estructura oracional con objeto directo antepuesto al verbo con especial atención al siglo XIX", "La historia del español. Propuesta de un tercer periodo evolutivo" (en coautoría con Chantal Melis y Marcela Flores) y "Estructura y evolución de las oraciones completivas de sustantivo en el español" (en coautoría con Concepción Company). Y entre sus capítulos destacan, sobre el español actual, "Las oraciones subordinadas sustantivas enunciativas (o completivas) de predicado nominal. Estructura y función", "La frase nominal de objeto directo antepuesta al verbo en español", "La estructura de la cláusula. Hacia una metodología de análisis sintáctico" y "El estatus del clítico de complemento indirecto en español"; sobre la historia interna del español, los tres capítulos con los que participó en los tres tomos de la Sintaxis histórica de la lengua española (dirigida por Concepción Company): "Oraciones subordinadas sustantivas enunciativas de sujeto, predicado nominal y régimen prepositivo", "La frase nominal con núcleo sustantivo común" y "El clítico se. Valores y evolución”; y sobre historia externa, su capítulo en la Historia sociolingüística de México (dirigida por Rebeca Barriga y Pedro Martín): "Del choque intercultural a la génesis del español novohispano", así como "El léxico indígena en la conformación del español novohispano temprano".

Finalmente, y en otro orden de cosas, fue prosecretario, secretario y presidente de la Asociación Mexicana de Lingüística Aplicada. Ha sido miembro del Consejo de Redacción 
de la Nueva Revista de Filología Hispánica, y es miembro del Consejo Editorial de las revistas Dimensión Antropológica y Cuicuilco, del Instituto Nacional de Antropología e Historia. Recientemente fue Coordinador Académico del Centro de Estudios Lingüísticos y Literarios (2009-2015). Es miembro del Sistema Nacional de Investigadores. 